\title{
Sensibilidad de Elmidae (Insecta: Coleoptera) a la perturbación del hábitat y la calidad fisicoquímica del agua en ambientes lóticos de los Andes colombianos
}

\author{
Marcela González-Córdoba ${ }^{1,2, *}$, María del Carmen Zúñiga ${ }^{1,2}$, Lina Paola Giraldo ${ }^{1}$ \& \\ Yuly Paulina Ramírez ${ }^{1}$, Julián Chará ${ }^{1}$ \\ 1. Centro para la Investigación en Sistemas Sostenibles de Producción Agropecuaria CIPAV. Carrera 25 No. 6-62, Cali, \\ Colombia; margocologa5@gmail.com,maczuniga@gmail.com,lina@fun.cipav.org.co, \\ yulypaulinaramirez@gmail.com, julian@fun.cipav.org.co \\ 2. Grupo de Investigaciones Entomológicas, Departamento de Biología, Universidad del Valle, AA 25360. Cali, \\ Colombia; marcela.gonzalez@correounivalle.edu.co, ORCID: 0000-0003-1397-6056 \\ * Correspondencia.
}

Recibido 03-X-2019. Corregido 09-I-2020. Aceptado 27-II-2020.

\begin{abstract}
Sensitivity of Elmidae (Insecta: Coleoptera) to habitat disturbance and physicochemical water quality in lotic environments of the Colombian Andes. Introduction: Riffle beetles are aquatic organisms frequently associated with well-oxygenated clean running water. However, some genera of Elmidae can also be found in moderately polluted streams proving their tolerance to certain degree of habitat degradation. Objective: To determine the pollution sensitivity and tolerance of each genus of Elmidae in Colombian streams, and the main factors that influence its presence and taxonomic composition. Methods: Sixty locations between 450 and 4000 m.a.s.l. were sampled, mainly in the Andean Region of Colombia. Collection was carried out between 2002 and 2013 with 70 non-simultaneous events in five zones. In a $100 \mathrm{~m}$ transect, physicochemical, bacteriological and environmental quality information was recorded. Samples of Elmidae were collected with D and Surber nets and determined taxonomically. A Canonical Correspondence Analysis of the Elmidae assembly and environmental data was carried out, significant relationships were confirmed with a Mantel test and a partial Mantel test was carried out including the geographic location as the third matrix. The Pollution (ICO) and Water Quality (ICA-NSF) Indices were calculated, and the occurrence intervals by genus were plotted for environmental variables and indices. Analysis of Variance ANOVA, Student's t-test and Generalized Linear Models GLM with Poisson distribution, were calculated in order to establish the significance of the results. Results: Twenty-two genera and 15 species were found in the evaluated streams; which represent $78.5 \%$ of known national generic richness. Tyletelmis and the species Gyrelmis pusio, G. simplex, Xenelmis sandersoni, X. leechi, $X$. granatoides and $X$. teres correspond to new records for Colombia. The most important factors influencing the presence and composition of Elmidae were: oxygen saturation, sediment deposition, suspended solids, epifaunal substrate availability, altitude and geographic location, conductivity, turbidity, alkalinity, nitrates, ammonia nitrogen and phosphorus. Conclusions: The genera of Elmidae differ in their tolerance to contamination and therefore cannot be classified in the same degree of sensitivity. This information can be useful for classifying genera of Elmidae according to their sensitivity to changes in environmental conditions and habitat degradation, which will be a first step to incorporate Elmidae in water quality biotic indices adapted to local conditions or to adjust preexisting indices.
\end{abstract}

Key words: riffle beetles, lotic, dissolved oxygen, freshwater quality, pollution.

González-Córdoba, M., Zúñiga, M.C., Giraldo, L.P., \& Ramírez, Y.P., Chará, J. (2020). Sensibilidad de Elmidae (Insecta: Coleoptera) a la perturbación del hábitat y la calidad fisicoquímica del agua en ambientes lóticos de los Andes colombianos. Revista de Biología Tropical, 68(2), 601-622. 
La familia Elmidae (Insecta: Coleoptera) corresponde a un grupo de coleópteros acuáticos a semiacuáticos presente en una amplia gama de ecosistemas; desde aguas muy limpias, correntosas y oxigenadas, pasando por ambientes lóticos de poca corriente, zonas termales, aguas subterráneas, algunos ambientes lénticos, hasta ríos con grados moderados de contaminación (Spangler, 1980, 1981; GarcíaCriado, Fernández-Aláez, \& Fernández-Aláez, 1999; García-Criado, 2000; Dos Santos, Molineri, Reynaga, \& Basualdo, 2011). Este grupo tiene gran potencial como bioindicador y experimenta una creciente inclusión en estudios de calidad de agua, puesto que tanto larvas como adultos son abundantes y frecuentes en gran variedad de microhábitats lóticos y su taxonomía a nivel de género está relativamente resuelta. Además, pueden dar una idea de las perturbaciones a mediano y largo plazo por sus ciclos de vida largos y su persistencia en los hábitats colonizados, los cuales suelen ser ambientes conservados (Brown, 1991; Von Ellenrieder, 2007; Dos Santos et al., 2011).

El alto requerimiento de oxígeno disuelto en el agua es una de las principales razones para que se reconozca a la familia Elmidae por su sensibilidad a la contaminación (Passos, Nessimian, \& Dorvillé, 2003), pues se consideran más específicos de aguas limpias. Sin embargo, su eficiencia y mecanismos de respiración pueden variar dependiendo de la especie y el estado de desarrollo (Brown, 1984). Todas las larvas de la familia Elmidae son acuáticas y obtienen el oxígeno a través de filamentos branquiales localizados en la región anal. Los hábitos y respiración en adultos pueden variar entre las dos subfamilias hasta ahora reconocidas, Elminae y Larainae, las cuales pueden ser diferenciadas por algunas características morfológicas y ecológicas (Brown, 1984; Jäch, Kodada, Brojer, Shepard, \& Čiampor, 2016). Los laráineos adultos generalmente habitan ambientes húmedos como zonas de salpicadura, riberas, rápidos, cascadas o se encuentran sumergidos en el agua, en donde respiran aire atmosférico o retienen burbujas temporales de aire que renuevan en la superficie (Stride,
1955; Brown, 1981, 1987). Los elmíneos adultos son acuáticos verdaderos y su respiración es asistida por una burbuja permanente de aire adherida a una capa de finas setas hidrófugas llamadas tomento. El contenido de oxígeno en la burbuja se renueva por difusión del oxígeno sin salir a la superficie, gracias a las presiones parciales de gases $\left(\mathrm{N}_{2}, \mathrm{O}_{2}\right.$ y $\left.\mathrm{CO}_{2}\right)$ que crean un gradiente entre el interior y el exterior de la burbuja. Por lo tanto, estos organismos pueden ser más susceptibles a la disminución del oxígeno disuelto, el aumento de nutrientes y la temperatura del agua, que intervienen en el mantenimiento del gradiente, o a factores que afecten la retención de la burbuja o plastrón, como la contaminación por detergentes y los sólidos suspendidos (Brocher, 1912; Harpster, 1944; Brown, 1984).

En comparación con otros coleópteros acuáticos, Elmidae se considera un grupo relativamente homogéneo en cuanto a rasgos biológicos y ecológicos (Picazo, Millán, \& Dolédec, 2012). Sin embargo, gran parte de la información ecológica sobre Elmidae, se extrae de estudios sobre macroinvertebrados acuáticos, muchas veces a nivel de familia, en donde se incluyen los géneros más comunes, que en Colombia serían: Heterelmis, Macrelmis, y Cylloepus (González-Córdoba, Zúñiga, \& Manzo, 2015; Roldán-Pérez, 2016; Hincapié-Montoya, 2017; Lozano-Bravo, Guevara-Cardona, \& Reinoso-Flórez, 2018). La distribución, supervivencia, requerimientos de hábitat y espectros de tolerancia de Elmidae pueden variar al profundizar en una clasificación más fina, discriminando géneros o especies (García-Criado, 2000). Por lo tanto, los datos ecológicos disponibles en Colombia no siempre son congruentes con la variabilidad morfológica y ecológica que exhiben en el país y el Neotrópico (Manzo, 2013; GonzálezCórdoba, Zúñiga, Manzo, Granados-Martínez, \& Panche, 2019).

Por lo anterior, el presente estudio busca analizar el efecto de algunos factores ambientales sobre la distribución y supervivencia de los géneros de Elmidae en cuerpos lóticos de bajo orden (1-3) en Los Andes colombianos. 
Asimismo, se intenta definir la sensibilidad o tolerancia de cada género a los niveles de calidad de agua (en función de los índices de contaminación y calidad de agua ICA-NSF e ICOs) y discriminar entre las respuestas a las condiciones físico-químicas del agua (Ott, 1978; Ramírez, Restrepo, \& Viña-Viscaíno 2000). Bajo este objetivo, se plantea la hipótesis de que existe variabilidad intrafamiliar en las respuestas ecológicas de Elmidae frente a los cambios de su hábitat y que existen grupos más vulnerables a las perturbaciones del medio, los cuales pueden ser definidos como sensibles y grupos menos vulnerables que pueden ser definidos como tolerantes. Igualmente, dados los antecedentes de la familia, se espera que el oxígeno sea el factor más importante que limite la persistencia de la familia en arroyos andinos colombianos.

\section{MATERIALES Y MÉTODOS}

Área de estudio: Los sitios de muestreo corresponden a 60 arroyos (corrientes de agua de primer a tercer orden) de cauce pequeño a mediano $(0.40$ a $6.30 \mathrm{~m}$ de ancho húmedo y 0.03 a $1.50 \mathrm{~m}$ de profundidad), ubicadas en 20 municipios de ocho departamentos de Colombia. Estos afluentes drenan en las macrocuencas de los ríos Cauca, Magdalena y Orinoco (Fig. 1, Tabla 1), que pertenecen a la Región Andina y Orinoquía. La zona de estudio se dividió en cinco ventanas de muestreo (Fig. 1, Tabla 1) que comprendieron altitudes entre 450 y 4000 m.s.n.m., en donde se presentan diferentes grados de influencia agrícola en su área de captación y zona ribereña, de tal forma que se clasifican como bosque, suelo ganadero o agrícola cafetero.

Recolección de especímenes: Las recolecciones incluyeron 70 eventos de muestreo no simultáneo entre 2002 y 2013. En cada sitio de estudio se realizaron 20 arrastres con red tipo D a lo largo un transecto de $100 \mathrm{~m}$, abarcando la mayor cantidad de sustratos disponibles en cada corriente hídrica. Además, se tomaron cinco muestras usando una red tipo
Surber con un área de barrido de 30 x $30 \mathrm{~cm}$, malla con poro de $500 \mu \mathrm{m}$ y el tiempo de muestreo estandarizado en un minuto. El material recolectado se separó y fijó en etanol al $80 \%$ para su posterior identificación.

Determinación taxonómica: Los élmidos se determinaron al menor nivel taxonómico posible utilizando las claves para identificación de géneros de Manzo (2005) y Manzo y Archangelsky (2008). Para la determinación de especies se extrajo el aparato genital masculino, se aclaró en ácido láctico al $80 \%$ y se utilizaron las claves y descripciones originales disponibles (i.e. Hinton, 1939, 1940a, 1940b, 1972; Delève, 1968; Brown, 1970, 1981, 1985; Spangler, 1990; Spangler \& Santiago, 1987, 1991; Spangler \& Perkins, 1989; Spangler \& Santiago-Fragoso, 1992; Manzo, 2006; Maier \& Spangler, 2011; Sampaio, Passos, \& Ferreira, 2015). Todos los especímenes recolectados están depositados en el Museo de Entomología de la Universidad del Valle (MUSENUV) en Cali, Colombia.

Toma de datos físico-químicos: En cada microcuenca de estudio se tomó una muestra puntual de agua que fue enviada a diferentes laboratorios especializados para los análisis de tipo físico-químico y conteos bacterianos. Otros parámetros fueron medidos en campo utilizando una sonda multiparamétrica YSI. Los parámetros de tipo físico-químico y bacteriológico analizados fueron: temperatura, $\mathrm{pH}$, oxígeno disuelto, porcentaje de saturación de oxígeno, conductividad, turbidez, alcalinidad total, alcalinidad bicarbonática, dureza total, nitritos, nitratos, nitrógeno amoniacal, nitrógeno total, fosfatos, fósforo total, $\mathrm{DBO}_{5}$ a $20{ }^{\circ} \mathrm{C}$, sólidos suspendidos totales, sólidos totales, sólidos disueltos totales, coliformes totales, Escherichia coli Escherich, 1885 y coliformes fecales.

Toma de datos de hábitat: En cada transecto de muestreo de $100 \mathrm{~m}$, se tomaron medidas de ancho y profundidad del cauce cada $50 \mathrm{~m}$ con una cinta métrica. Se estimó la 


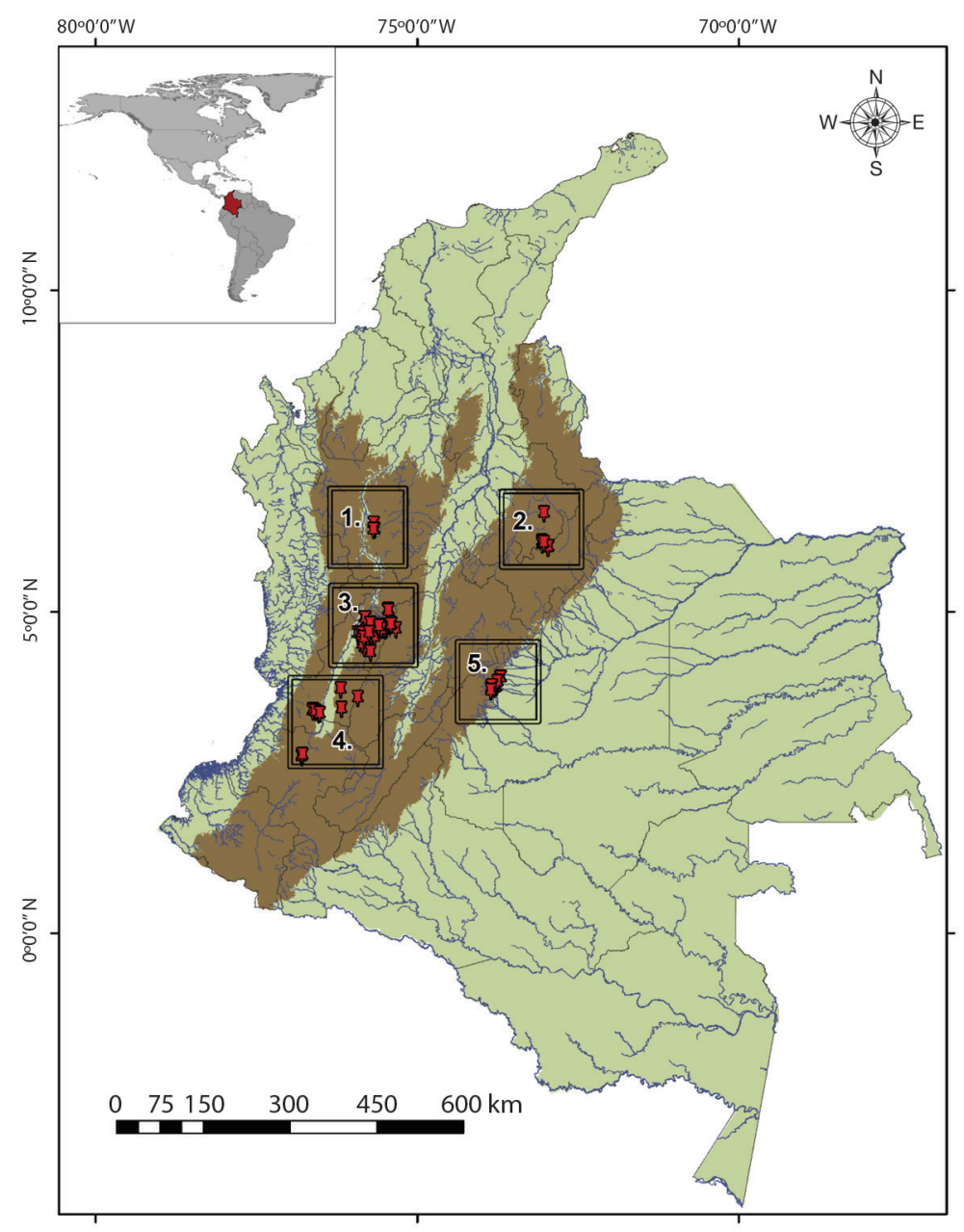

Fig. 1. Localidades para el muestreo de coleópteros acuáticos (Elmidae) en microcuencas de Colombia.

Fig. 1. Localities for the sampling of water beetles (Elmidae) in micro basins of Colombia.

cobertura de dosel cada $10 \mathrm{~m}$ con un densiómetro esférico. Se hicieron cálculos porcentuales del sustrato del fondo cada $5 \mathrm{~m}$, discriminando entre lodo, arcilla, limo, arena, grava, guijarros, cantos y roca madre. Se midió la longitud de los tramos de corriente con una cinta métrica, discriminando entre piscinas, corriente lenta, corriente rápida y turbulencias. Con esta información y la metodología propuesta por Barbour, Gerritsen, Snyder y Stribling (1999) y Chará (2003), se evaluaron los arroyos mediante el Índice de Calidad de Hábitat ICH adaptado por CIPAV. Se estimaron y ponderaron los siguientes parámetros: sustrato disponible para colonización de organismos, colmatación de espacios entre piedras, caracterización del sustrato en piscinas, combinación de velocidad y profundidad, diversidad de piscinas, deposición de sedimentos, estado del nivel del agua, perturbación del cauce, frecuencia de turbulencias, sinuosidad del cauce, estabilidad de las orillas, protección vegetal en orillas, zona de vegetación ribereña y la sumatoria del índice.

Análisis de datos: Se realizó una correlación de Pearson a partir de los datos físicoquímicos, calidad de agua, calidad de hábitat y caracterizaciones ambientales de los puntos de 


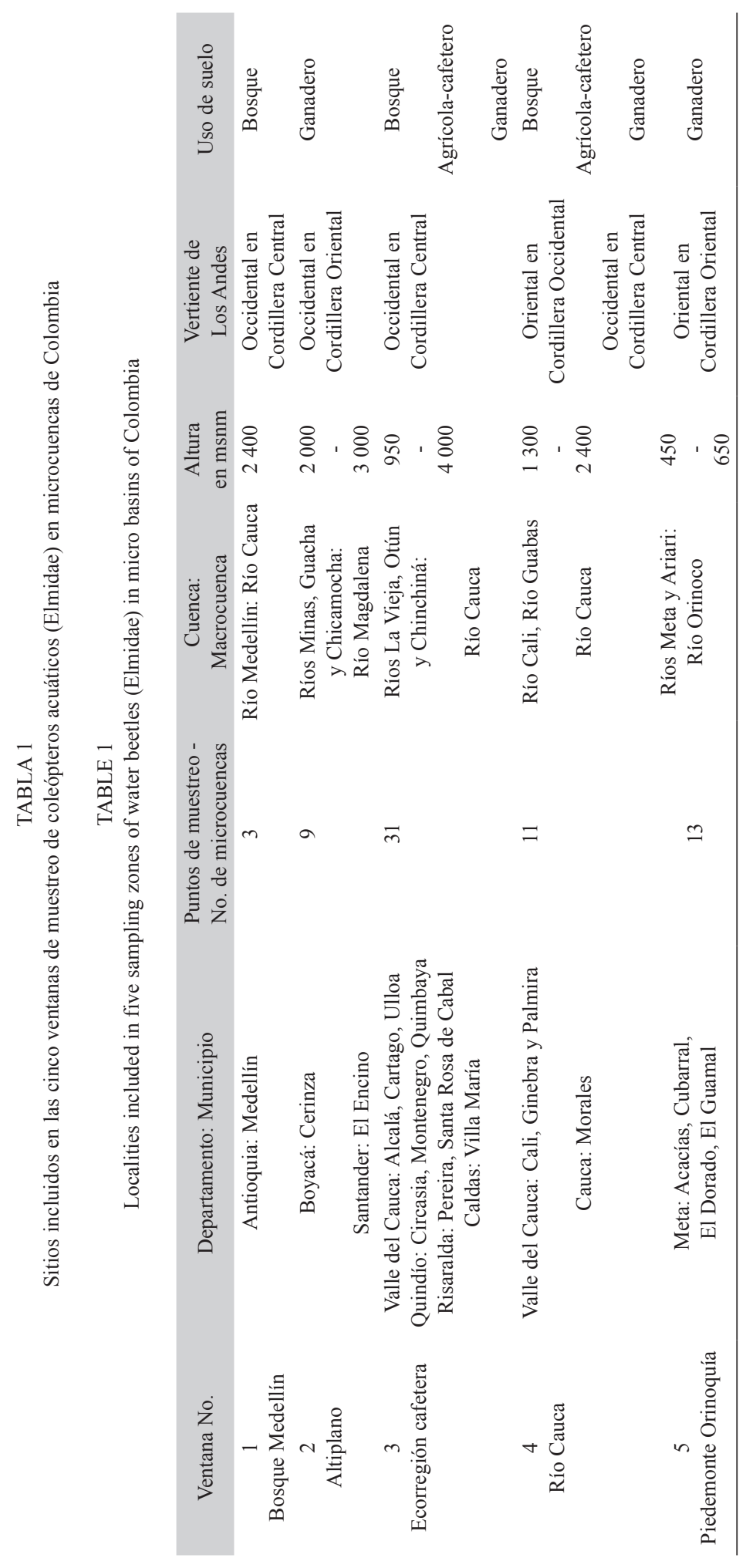


muestreo, para determinar variables altamente correlacionadas. (Análisis de correlación de Pearson, $\mathrm{R}>0.6, \mathrm{p}<0.05)$. Posteriormente entre aquellas que indicaron correlación, se seleccionó una como indicadora de las demás; dichas variables se incluyeron en un Análisis de Correspondencia Canónico CCA (por sus siglas en inglés) con la composición de los géneros de Elmidae. A partir del CCA se realizó un Análisis de Varianzas ANOVA para evaluar los factores o parámetros que más contribuyen en la composición, distribución o supervivencia de los géneros de Elmidae en la zona de estudio. Con las variables ambientales seleccionadas por su significancia en la ANOVA y los datos de composición de Elmidae se realizó una prueba de Mantel para determinar la influencia de las primeras sobre las segundas, seguida de una prueba de Mantel parcial incluyendo como tercera matriz los puntos geográficos para determinar hasta qué punto los patrones observados se deben al cambio entre localidades. Por último, se graficaron los primeros dos ejes de dos modelos de CCA en donde se incluyeron los datos de composición de organismos y los datos ambientales significativos. El primer modelo tuvo en cuenta las variables geográficas en grados decimales y el segundo modelo tomó las variables ambientales sin la interacción geográfica. Para este propósito se usaron el programa $\mathrm{R}$ y los paquetes Vegan e Indicspecies (De Cáceres \& Legendre, 2009; Oksanen et al., 2018; R Core Team, 2018).

Se tuvieron en cuenta datos cualitativos como uso de suelo, cobertura de ribera, sustrato y microhábitat, para intentar explicar la riqueza y composición de Elmidae en cada punto de muestreo en el espacio y el tiempo. Mediante el programa PAST (Hammer, Harper, \& Ryan, 2001), se realizó una prueba t de Student para comparar la riqueza y la abundancia en arroyos con ribera protegida vs. desprotegida, la riqueza de géneros en arroyos con sustrato grueso predominante (> $50 \%$ ) vs. no predominante, rechazando la hipótesis nula con $\alpha$ $=0.05$. Se analizó el efecto de las variables físico-químicas sobre el número de géneros de Elmidae encontrados en cada rango de valores por medio de Modelos Lineales Generalizados (MLG) con distribución Poisson. Los supuestos de normalidad y homocedasticidad se probaron con una prueba de Shapiro Wilks y Levene en el programa PAST.

Con base en la información recolectada y los protocolos establecidos se calcularon: el Índice de Calidad de Agua propuesto por la Fundación Nacional de Saneamiento de Estados Unidos (ICA-FSN) (Ott, 1978) y los Índices de Contaminación (ICOs) propuestos por Ramírez et al. (2000), que discriminan entre la contaminación orgánica (ICOMO), trófica (ICOTRO), por mineralización (ICOMI) y por sólidos (ICOSUS). Dichos índices fueron contrastados con la composición taxonómica y se graficaron los intervalos de presencia para cada género de Elmidae.

\section{RESULTADOS}

Se recolectaron 8954 individuos, de los cuales 4472 fueron adultos y 4482 larvas. Se determinaron 22 géneros: Austrelmis, Austrolimnius, Cylloepus, Disersus, Gyrelmis, Heterelmis, Hexacylloepus, Hexanchorus, Huleechius, Macrelmis, Microcylloepus, Neoelmis, Neolimnius, Notelmis, Onychelmis, Phanocerus, Pharceonus, Pseudodisersus, Stegoelmis, Stenhelmoides, Tyletelmis y Xenelmis.

Dentro de los géneros identificados, se determinaron 15 especies: Austrolimnius formosus (Sharp, 1882), Disersus inca Spangler y Santiago-Fragoso, 1987, Gyrelmis thoracica Hinton, 1940, G. pusio Hinton, 1940, G. simplex Hinton, 1940, Neolimnius palpalis Hinton, 1939, Notelmis nodipes (Sharp, 1882), $N$. bifoveolata Delève, 1968, Onychelmis leleupi Delève 1968, O. longicollis (Sharp, 1882), Pharceonus volcanus Spangler y SantiagoFragoso, 1992, Xenelmis sandersoni Brown, 1985, X. leechi Perkins y Steiner, 1981, X. granatoides Sampaio, dos Passos y Ferreira, 2015 y $X$. teres Hinton, 1946, más otras seis especies no identificadas y potencialmente nuevas de Austrelmis, Disersus, Huleechius, Onychelmis, Tyletelmis y Xenelmis. 
Los géneros más abundantes en los muestreos fueron Heterelmis (2952 ind. $33 \%$ ), Microcylloepus (1474 ind. $16 \%$ ), Macrelmis (964 ind. $11 \%$ ), Austrolimnius (813 ind. $9 \%$ ), Neoelmis (716 ind. $8 \%$ ) y Cylloepus (564 ind. $6 \%$ ), en contraste con tres individuos recolectados de Tyletelmis y dos de Stenhelmoides. Los géneros Disersus y Pseudodisersus presentaron únicamente individuos en estado de larva y Tyletelmis únicamente en estado adulto. Se encontraron representantes de la familia Elmidae en todos los ambientes evaluados entre 460 y $3947 \mathrm{msnm}$. Las cuencas con mayor riqueza fueron el río Meta (18 géneros, 1 especie y 3467 ind.) y el río Otún (16 géneros, 1 especie y 1315 ind.).

\section{Composición de Elmidae y calidad de} hábitat: Se encontró mayor abundancia $\mathrm{y}$ riqueza de Elmidae en los cuerpos de agua con bosque en la zona ribereña (5133 ind. y 21 géneros), en contraste con los arroyos de ribera desprotegida (3 821 ind. y 19 géneros) (prueba t, $\mathrm{P}<0.05$ ). Dos géneros de la subfamilia Larainae (Disersus y Pseudodisersus) y Stenhelmoides de la subfamilia Elminae, se encontraron únicamente en quebradas con algún grado de cobertura de dosel, mientras que un solo género de la subfamilia Elminae (Tyletelmis) se encontró exclusivamente en quebradas sin protección de ribera.

La composición de los sustratos en el fondo del río afectó la diversidad de élmidos en los arroyos evaluados (prueba t, $\mathrm{P}<0.05$ ). De esta forma, ríos con fondo cubierto por más del $30 \%$ de sustrato fino (arenas, arcillas y limos), presentaron menor cantidad de élmidos asociados. Asimismo, coberturas con más del $50 \%$ de sustratos gruesos (grava, guijarros, cantos), se relacionaron con un aumento en la diversidad de estos coleópteros.

Los élmidos tuvieron mayor predilección por el microhábitat conformado por piedras, donde se encontraron 22 géneros y 6402 individuos. La hojarasca albergó a 15 géneros y 683 individuos, seguido por las macrófitas con nueve géneros y 119 individuos, mientras que los microhábitats menos colonizados por estos organismos fueron arena y lodo. Por otro lado, ríos que presentaron combinación de corrientes rápidas y lentas, tuvieron mayor diversidad que aquellos ríos con altas proporciones de piscinas o turbulencias (sumatoria $\geq 40 \mathrm{~m}$ en el tramo evaluado).

Teniendo en cuenta el Índice de Calidad de Hábitat ICH, se encontró que valores altos, mayores a 12 puntos (máximo 20 puntos), para 'sustratos disponibles para la colonización de organismos', 'colmatación de espacios entre piedras' y 'deposición de sedimentos' coincidieron con un aumento en la riqueza y abundancia de la familia. Los demás aspectos del índice y la sumatoria de valores del ICH no mostraron un patrón de relación.

Variables ambientales y CCA: De las 62 variables ambientales, se descartaron 26 altamente correlacionadas con otras (Análisis de correlación de Pearson, $\mathrm{R}>0.6, \mathrm{P}<0.05$ ) y se incluyeron 36 como variables indicadoras. Un CCA con 36 variables indicadoras y los géneros de Elmidae encontrados, mostró que los parámetros estudiados explican en un 68 $\%$ la presencia de los élmidos (ANOVA, $\mathrm{F}_{36}$ $=2.9405, \mathrm{P}=0.015$ ). Teniendo en cuenta que la ubicación geográfica (latitud y longitud en grado decimales) tuvo un efecto significativo en el CCA (ANOVA, $\mathrm{F}_{1}=7.0287, \mathrm{P}=0.013$ ), se realizó un test parcial de Mantel que indicó que las variables ambientales se relacionan con las variables geográficas (test de Mantel, $\mathrm{R}=$ $0.08815, \mathrm{P}=0.0222$ ), afectando la distribución de los géneros de Elmidae.

A partir de la prueba CCA realizada anteriormente, se realizó un CCA en el cual se excluyeron las variables geográficas y se tuvieron en cuenta únicamente los parámetros físico-químicos y de calidad ambiental. Ambos modelos fueron significativos y explicaron el $75 \%$ de la varianza de los datos (Fig. 2). El primer modelo (ANOVA, $\mathrm{F}_{4}=8.2322, \mathrm{P}=$ 0.001) incluyó: longitud geográfica (ANOVA, $\left.\mathrm{F}_{1}=16.9739, \mathrm{P}=0.001\right)$, latitud decimal (ANOVA, $\mathrm{F}_{1}=6.4910, \mathrm{P}=0.002$ ), sólidos suspendidos totales (ANOVA, $\mathrm{F}_{1}=5.3121, \mathrm{P}=$ 0.006) y deposición de sedimentos (ANOVA, 
$\left.\mathrm{F}_{1}=4.1517, \mathrm{P}=0.010\right)$. El segundo modelo (ANOVA, $\left.\mathrm{F}_{4}=7.1942, \mathrm{P}=0.001\right)$ se graficó con las variables altitud (ANOVA, $\mathrm{F}_{1}=$ 17.2460, $\mathrm{P}=0.001$ ), fósforo total (ANOVA, $\left.\mathrm{F}_{1}=9.4077, \mathrm{P}=0.004\right)$, oxígeno disuelto (ANOVA, $\mathrm{F}_{1}=7.4256, \mathrm{P}=0.016$ ) y sustrato disponible para colonización de organismos

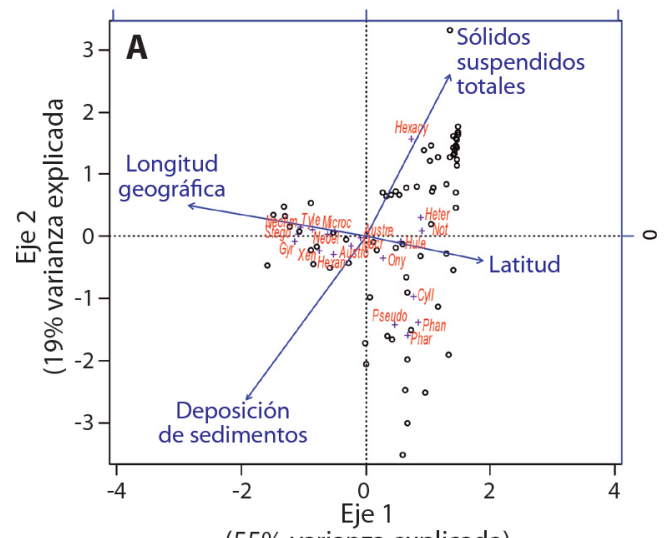

(55\% varianza explicada)

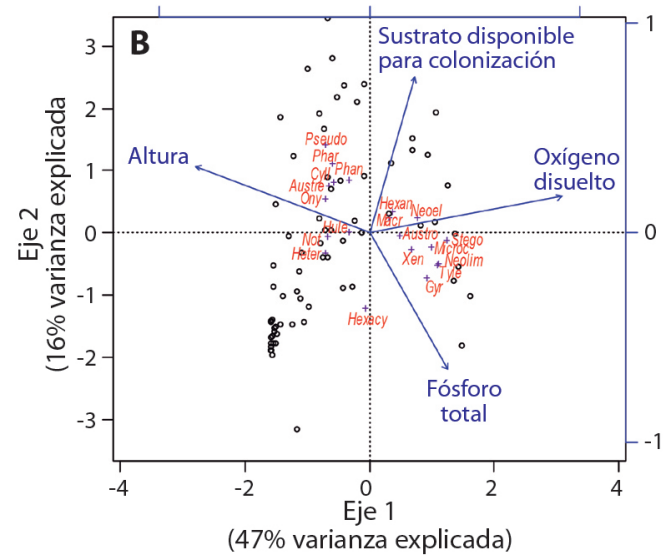

Fig. 2. Análisis de Correspondencia Canónico CCA de la composición de Elmidae en los Andes colombianos en función de las variables ambientales. Incluyendo (arriba) y excluyendo (abajo) las coordenadas geográficas A. altitud, saturación de oxígeno y sustratos disponibles para la colonización de organismos y B. latitud, longitud, sólidos suspendidos y deposición de sedimentos.

Fig. 2. Canonical Correspondence Analysis CCA of Elmidae composition from Colombian Andes in function of environmental variables. Including (above) and excluding (below) geographic coordinates.: A. elevation, oxygen saturation and substrates available for the colonization of organisms, and B. latitude, longitude, suspended solids and sediment deposition.
(ANOVA, $\mathrm{F}_{1}=6.6239, \mathrm{P}=0.031$ ). Un segundo test de Mantel confirmó que dichas variables ejercen un efecto significativo en la presencia de los élmidos en Colombia (Test de Mantel, R $=0.1722, \mathrm{P}=0.0003$ ).

Al realizar el CCA distinguiendo entre estadios de vida, tanto adultos como larvas fueron asociados nuevamente con la longitud geográfica (ANOVA, $\mathrm{F}_{1,5}=18.296, \mathrm{P}=0.001 \mathrm{y}$ $\mathrm{F}_{1,5}=13.833, \mathrm{P}=0.001$ ), latitud (ANOVA, $\mathrm{F}_{1}$, $\left.{ }_{5}=7.902, \mathrm{P}=0.006 \mathrm{y} \mathrm{F}_{1,5}=6.092, \mathrm{P}=0.013\right)$, altitud (ANOVA, $\mathrm{F}_{1,5}=6.001, \mathrm{p}=0.011 \mathrm{y} \mathrm{F}_{1}$, $\left.{ }_{5}=10.0862, \mathrm{p}=0.001\right)$ y el oxígeno disuelto

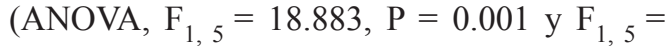
$4.448, \mathrm{P}=0.033$ ), en donde este último es más determinante para adultos que para larvas. Exclusivamente, las larvas se asociaron también con la valoración del ICH para la deposición de sedimentos (ANOVA, $\mathrm{F}_{1,5}=6.625$, $\mathrm{P}=0.002$ ), mientras que los adultos fueron afectados por los sólidos suspendidos totales (ANOVA, $\mathrm{F}_{1,5}=7.218, \mathrm{P}=0.010$ ).

Intervalos de presencia/ausencia en variables físico-químicas del agua: Teniendo en cuenta únicamente la riqueza y los valores de presencia/ausencia, se realizaron análisis de Modelos Lineales Generalizados (MGL) para las variables físico-químicas y bacteriológicas. Se encontró que la conductividad, alcalinidad, turbidez, nitratos, nitrógeno amoniacal y fósforo (Fig. 3C, Fig. 3D, Fig. 4A, Fig. 4B, Fig. 4C, Fig. 4D, Apéndice 1A, Apéndice 1B, Apéndice 1C, Apéndice 1D, Apéndice 1E), también influyeron de manera tangible en la riqueza de Elmidae en arroyos colombianos (MLG, P < 0.05). Variables como temperatura, $\mathrm{pH}$, nitrógeno total, nitritos, fosfatos, dureza, DBO y conteos bacterianos, no ejercieron un efecto significativo (MLG, P > 0.05) sobre la diversidad de la familia. Los límites superiores y la amplitud de los intervalos de aparición de los géneros fueron relativamente similares y consistentes comparando las variables evaluadas. De manera que los géneros Cylloepus, Heterelmis, Huleechius, Macrelmis, Microcylloepus y Neoelmis, mantuvieron los intervalos 

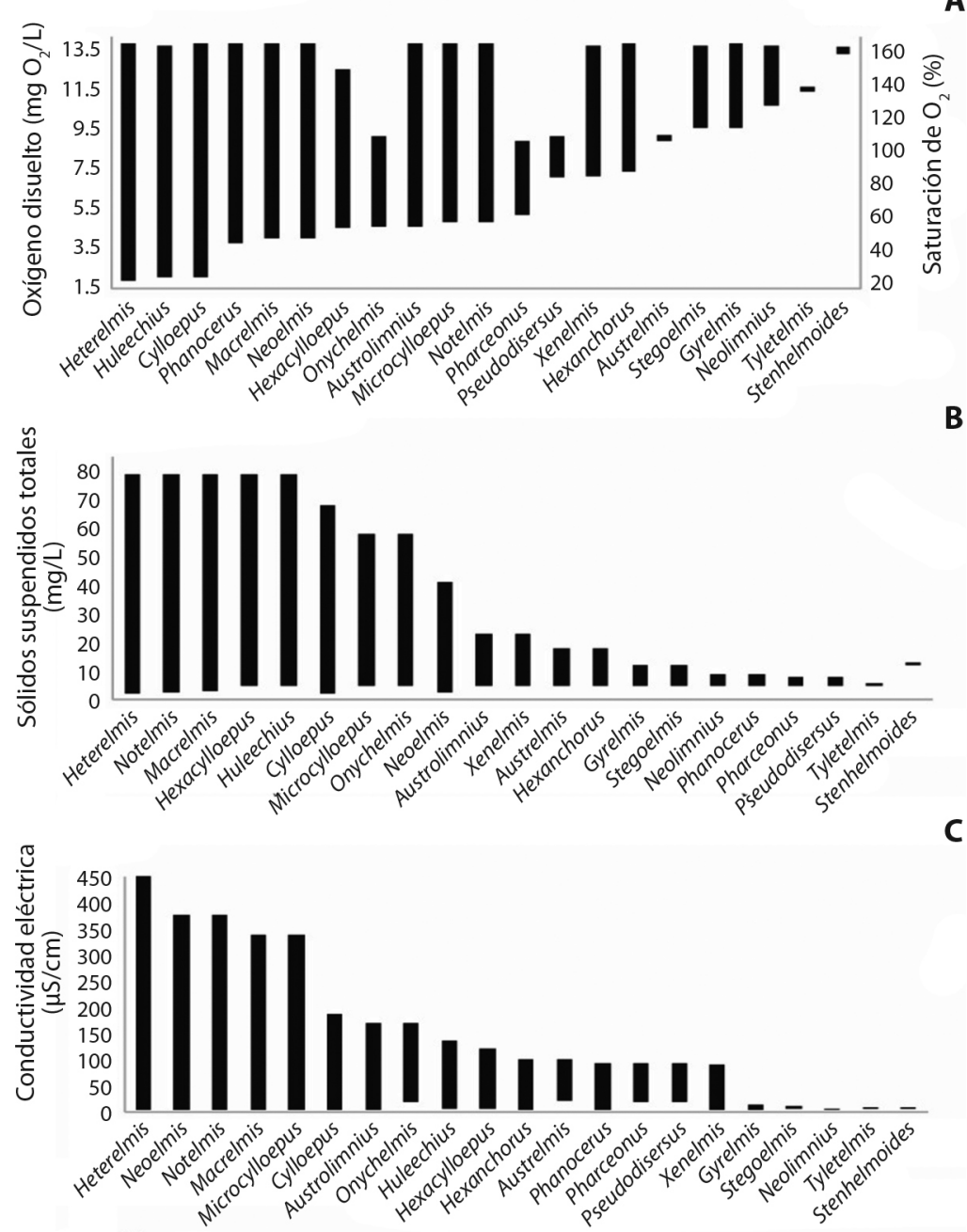

C

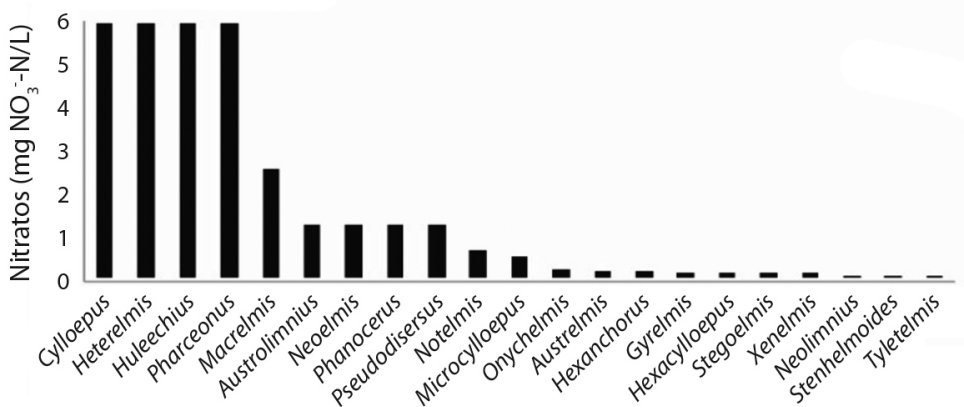

Fig. 3. Intervalos de aparición de los géneros de Elmidae para A. oxígeno disuelto y porcentaje de saturación de oxígeno, B. sólidos suspendidos totales, C. conductividad eléctrica y D. nitratos.

Fig. 3. Occurrence intervals of Elmidae genera for A. dissolved oxygen and oxygen saturation, B. total suspended solids, C. electric conductivity and $\mathbf{D}$. nitrates. 

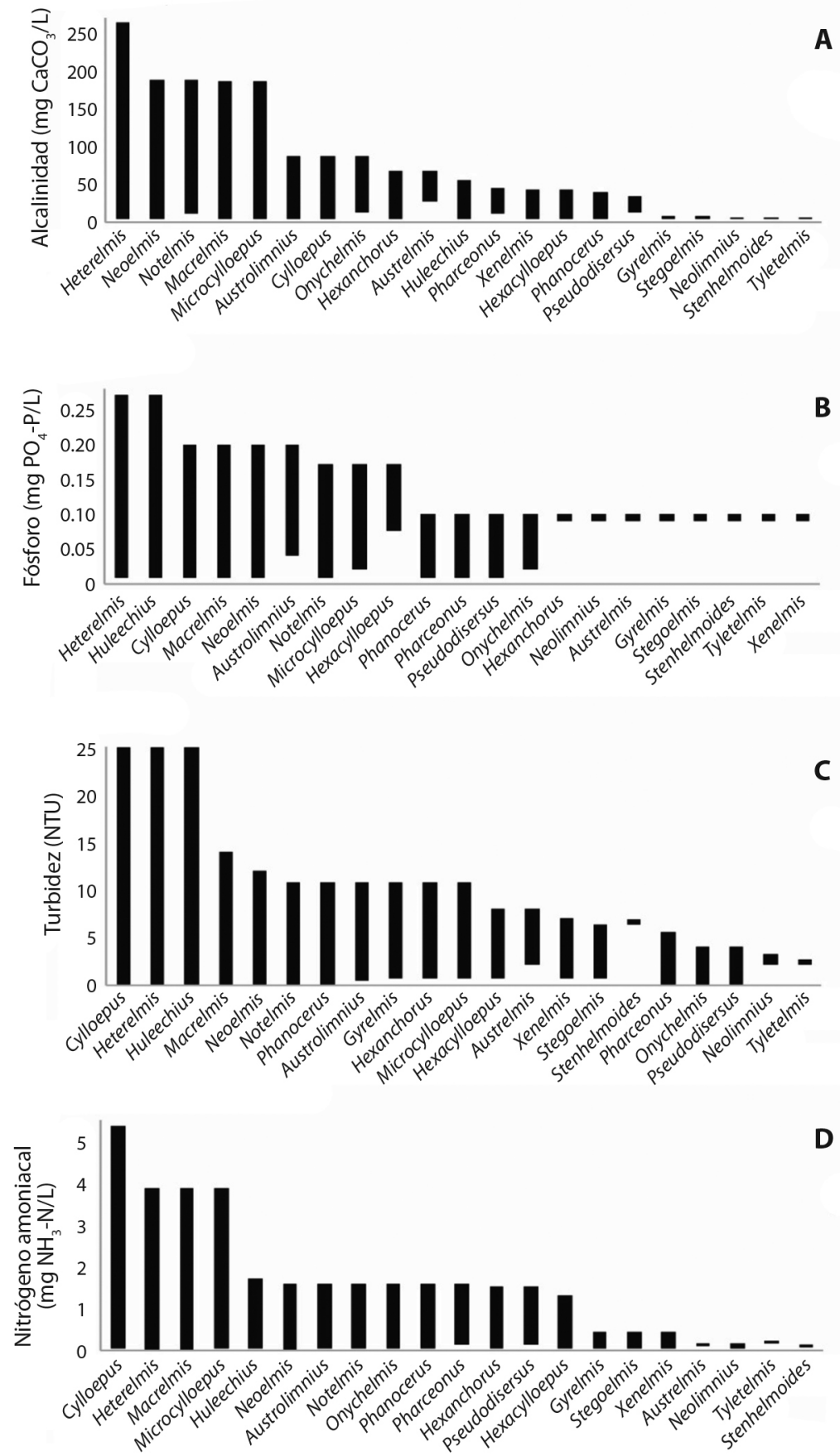

Fig. 4. Intervalos de aparición de los géneros de Elmidae para (A). alcalinidad, (B). fósforo, (C). turbidez y (D). nitrógeno amoniacal.

Fig. 4. Occurrence intervals of Elmidae genera for (A). alkalinity, (B). phosphorus, (C). turbidity and (D). ammoniacal nitrogen. 
de variación más amplios para los diferentes parámetros físico-químicos (Fig. 3, Fig. 5).

En cuanto a la disponibilidad de oxígeno, la máxima concentración osciló entre 7 y 12 mg de oxígeno por litro de agua, en donde los mayores valores se presentaron en aguas de baja altitud en el pie de monte Orinoquense (Fig. 3A). Todos los géneros estuvieron representados en aguas con porcentajes de saturación de oxígeno mayores al $100 \%$ (sobresaturadas) y se encontró que no hay un valor máximo de oxígeno que imposibilite la supervivencia de Elmidae (Fig. 3A), sino que el límite superior es impuesto por el medio y la solubilidad en el agua. Por su parte, los valores inferiores tanto para la concentración $(\mathrm{mg} / \mathrm{L})$ como el porcentaje de saturación del oxígeno, dependieron de la sensibilidad de cada género a la hipoxia. Géneros como Hexanchorus, Pseudodisersus y Xenelmis, mostraron una alta afinidad por porcentajes de saturación de oxígeno altos, por encima del $90 \%$ y se destaca que los géneros Austrelmis, Gyrelmis, Neolimnius, Stegoelmis, Stenhelmoides y Tyletelmis, se encontraron exclusivamente en aguas sobresaturadas y con más de $9 \mathrm{mg} / \mathrm{L}$ de oxígeno disuelto. Austrolimnius, Hexacylloepus, Macrelmis, Microcylloepus, Neoelmis, Notelmis, Onychelmis, Phanocerus y Pharceonus tuvieron límites inferiores de oxígeno disuelto entre 4 y $5 \mathrm{mg} / \mathrm{L}$,

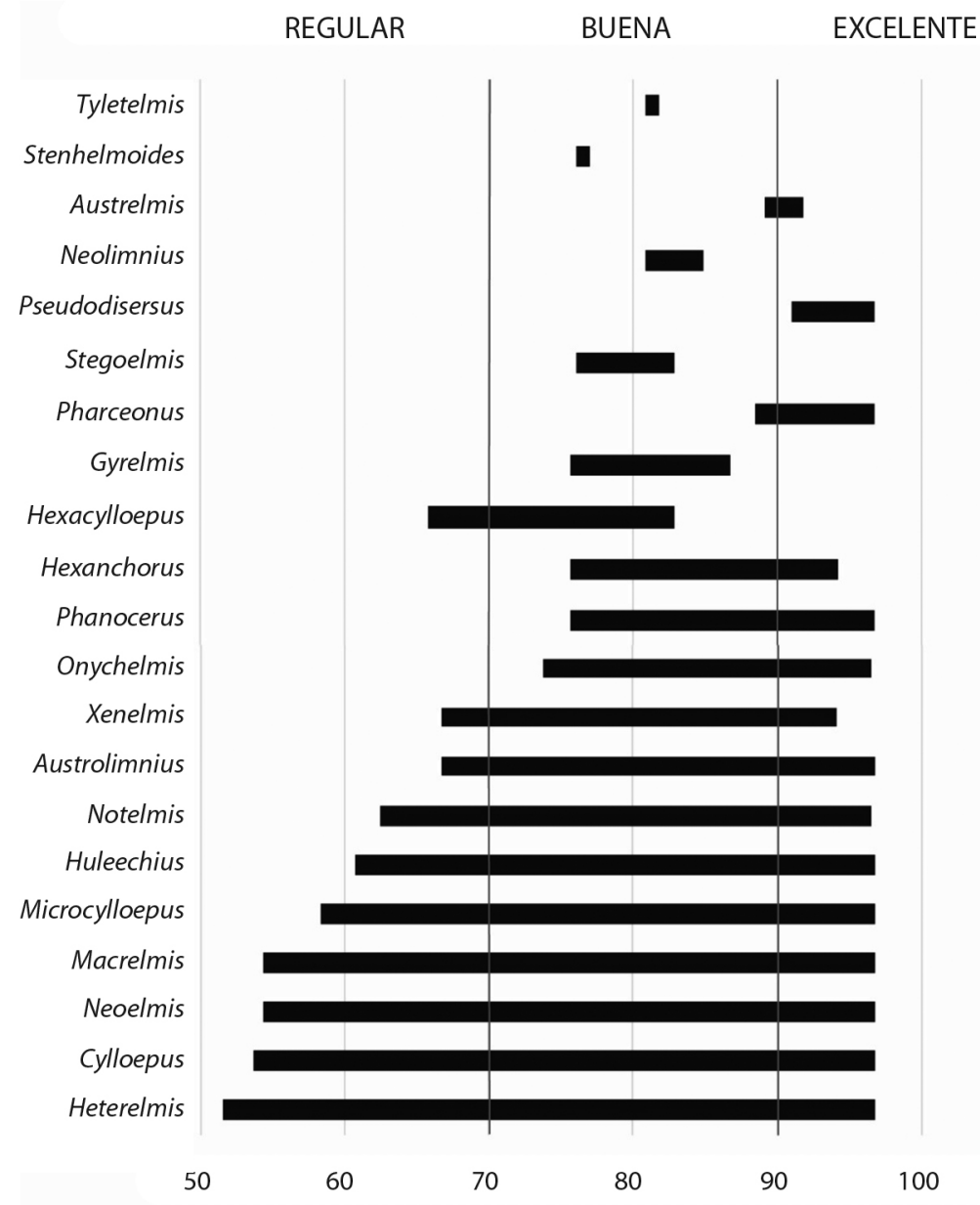

Fig. 5. Intervalos de aparición de los géneros de Elmidae en Los Andes colombianos según los índices ICA-NSF.

Fig. 5. Occurrence intervals of Elmidae genera in the Colombian Andes according to ICA-NSF. 
y entre 40 y $60 \%$ de saturación. Además, Cylloepus, Heterelmis y Huleechius, se mostraron tolerantes a la hipoxia $\left(\geq 5 \mathrm{mg} / \mathrm{L}\right.$ de $\mathrm{O}_{2}$ ) hasta niveles menores al $30 \%$ de saturación de oxígeno (Fig. 3A).

La cantidad de sólidos suspendidos y la deposición de sedimentos afectaron significativamente la presencia de los élmidos en los arroyos muestreados, de manera que se generaron dos grupos a partir del umbral de $20 \mathrm{mg} / \mathrm{L}$ (Fig. 3B). Austrelmis, Austrolimnius, Gyrelmis, Hexanchorus, Neolimnius, Phanocerus, Pharceonus, Pseudodisersus, Stegoelmis y Xenelmis, fueron sensibles al aumento de sólidos no solubles. Mientras que Cylloepus, Heterelmis, Hexacylloepus, Huleechius, Macrelmis, Microcylloepus, Notelmis y Onychelmis, toleraron mayores cantidades de partículas sedimentables y en suspensión. Además, Heterelmis, Notelmis y en mayor medida Hexacylloepus, presentaron afinidad por valores altos de esta variable en el CCA (Fig. 2).

Relacionado con lo anterior, en términos generales, los élmidos evaluados se encontraron en agua con poca turbidez $(\approx 10 \mathrm{UNT})$. Sin embargo, Cylloepus, Heterelmis y Huleechius, géneros que consistentemente se mostraron poco sensibles a la contaminación, se encontraron en aguas con cerca de 25 UNT (Fig. 4C).

En este trabajo se observó que algunos géneros de Elmidae sobreviven en un rango de temperatura estrecho, ya sea en aguas frías como en el caso de Austrelmis o en aguas cálidas como es el caso Gyrelmis, Hexacylloepus, Neolimnius, Stegoelmis, Stenhelmoides y Tyletelmis. Algunos géneros tienen espectros más amplios, entre 15 y $27{ }^{\circ} \mathrm{C}$ como Microcylloepus, Phanocerus y Xenelmis, o entre 12 y $22{ }^{\circ} \mathrm{C}$ como Notelmis, Pharceonus y Pseudodisersus. Mientras que géneros como Austrolimnius, Hexanchorus, Huleechius, Macrelmis, Neoelmis y, en especial, Cylloepus y Heterelmis, sobrevivieron en rangos de temperatura muy amplios y habitan tanto aguas frías como cálidas; desde los $10{ }^{\circ} \mathrm{C}$ hasta los $25{ }^{\circ} \mathrm{C}$, incluso hasta $27^{\circ} \mathrm{C}$ en los últimos dos géneros.

$\mathrm{Al}$ igual que la temperatura, el $\mathrm{pH}$ fue un parámetro con poca significancia estadística
(MLG, P > 0.05) para explicar la presencia de Elmidae en las corrientes. No obstante, se encontraron géneros propios de aguas ácidas como Gyrelmis, Hexacylloepus, Neolimnius, Stegoelmis, Tyletelmis y Xenelmis, con $\mathrm{pH}$ alrededor de 6 unidades y algunos géneros propios de aguas más alcalinas (entre 7.5 y 8.5 unidades de $\mathrm{pH}$ ) como Pseudodisersus, Pharceonus, Onychelmis, Notelmis y Austrelmis.

Índices de contaminación y calidad del agua: De acuerdo con los índices de calidad de agua ICA-NSF y de contaminación ICOs, la familia Elmidae se distribuyó desde aguas muy limpias hasta aguas moderadamente contaminadas. Los géneros Austrolimnius, Cylloepus, Heterelmis, Hexacylloepus, Huleechius, Macrelmis, Microcylloepus, Neoelmis, Notelmis, Onychelmis y Xenelmis, toleraron cierto grado de contaminación del agua (calidad regular). Mientras que los géneros Austrelmis, Gyrelmis, Hexanchorus, Neolimnius, Onychelmis, Phanocerus, Pharceonus, Pseudodisersus, Stegoelmis, Stenhelmoides y Tyletelmis, se encontraron exclusivamente en aguas limpias con calidad buena a excelente (Fig. 5).

Ninguno de los géneros estuvo presente en aguas con contaminación por sólidos suspendidos; la mayoría se encontró en intervalos inferiores a 0.2 unidades del índice ICOSUS y sólo Heterelmis, Hexacylloepus, Huleechius, Macrelmis y Notelmis, hasta 0.21 unidades (Tabla 2). La mayoría de géneros de Elmidae se asociaron con aguas con bajos niveles de contaminación orgánica y algunos toleraron un aumento moderado de la contaminación. Los géneros con menor tolerancia corresponden a Austrelmis, Hexacylloepus, Stenhelmoides y Tyletelmis, con intervalos inferiores a 0.4 en el índice ICOMO y únicamente Heterelmis alcanzó valores ligeramente por encima de 0.6 unidades (Tabla 2).

Se encontró una tendencia general de la presencia de Elmidae en aguas blandas y poco alcalinas; no obstante, los géneros Heterelmis, Macrelmis, Microcylloepus, Neoelmis y Notelmis, toleraron grados medios a altos de contaminación por mineralización, por encima 
TABLA 2

Intervalos de aparición de los géneros de Elmidae a los índices de contaminación del agua

TABLE 2

Occurrence intervals for pollution indices by genus of Elmidae

\begin{tabular}{|c|c|c|c|c|c|c|c|c|c|}
\hline \multirow{2}{*}{ Género } & \multicolumn{2}{|c|}{ ICOSUS } & \multicolumn{2}{|c|}{ ICOMO } & \multicolumn{2}{|c|}{ ICOMI } & \multicolumn{3}{|c|}{ ICOTRO } \\
\hline & Mín. & Máx. & Mín. & Máx. & Mín. & Máx. & Eut. & Meso. & Olig. \\
\hline Austrelmis & 0 & 0.034 & 0.223 & 0.320 & 0.010 & 0.151 & $\mathrm{X}$ & & \\
\hline Austrolimnius & 0 & 0.049 & 0 & 0.498 & 0.001 & 0.243 & $\mathrm{X}$ & & \\
\hline Cylloepus & 0 & 0.184 & 0 & 0.595 & 0.001 & 0.250 & $\mathrm{X}$ & $X$ & $X$ \\
\hline Gyrelmis & 0 & 0.016 & 0.289 & 0.498 & 0.001 & 0.006 & $\mathrm{X}$ & & \\
\hline Heterelmis & 0 & 0.217 & 0.001 & 0.607 & 0.001 & 0.667 & $\mathrm{X}$ & $\mathrm{X}$ & $X$ \\
\hline Hexacylloepus & 0 & 0.217 & 0.275 & 0.369 & 0.001 & 0.113 & $\mathrm{X}$ & & \\
\hline Hexanchorus & 0 & 0.034 & 0.223 & 0.498 & 0.001 & 0.151 & $\mathrm{X}$ & & \\
\hline Huleechius & 0 & 0.217 & 0 & 0.557 & 0.001 & 0.132 & $\mathrm{X}$ & $\mathrm{X}$ & $\mathrm{X}$ \\
\hline Macrelmis & 0 & 0.217 & 0 & 0.573 & 0.001 & 0.560 & $\mathrm{X}$ & $\mathrm{X}$ & $\mathrm{X}$ \\
\hline Microcylloepus & 0 & 0.154 & 0 & 0.498 & 0.001 & 0.560 & $\mathrm{X}$ & $\mathrm{X}$ & \\
\hline Neoelmis & 0 & 0.103 & 0 & 0.573 & 0.001 & 0.564 & $\mathrm{X}$ & $\mathrm{X}$ & $\mathrm{X}$ \\
\hline Neolimnius & 0 & 0 & 0.362 & 0.428 & 0.001 & 0.002 & $\mathrm{X}$ & & \\
\hline Notelmis & 0 & 0.217 & 0.017 & 0.418 & 0.001 & 0.564 & $\mathrm{X}$ & $\mathrm{X}$ & $X$ \\
\hline Onychelmis & 0 & 0.154 & 0.018 & 0.418 & 0.008 & 0.243 & $\mathrm{X}$ & $\mathrm{X}$ & $\mathrm{X}$ \\
\hline Phanocerus & 0 & 0 & 0 & 0.418 & 0.001 & 0.079 & $\mathrm{X}$ & $\mathrm{X}$ & $\mathrm{X}$ \\
\hline Pharceonus & 0 & 0 & 0.003 & 0.408 & 0.008 & 0.079 & $\mathrm{X}$ & $\mathrm{X}$ & $\mathrm{X}$ \\
\hline Pseudodisersus & 0 & 0 & 0 & 0.418 & 0.008 & 0.079 & $\mathrm{X}$ & & $\mathrm{X}$ \\
\hline Stegoelmis & 0 & 0.016 & 0.289 & 0.498 & 0.001 & 0.005 & $X$ & & \\
\hline Stenhelmoides & 0.016 & 0.016 & 0.364 & 0.364 & 0.001 & 0.002 & $X$ & & \\
\hline Tyletelmis & 0 & 0 & 0.362 & 0.361 & 0.002 & 0.002 & $X$ & & \\
\hline Xenelmis & 0 & 0.049 & 0.269 & 0.498 & 0.001 & 0.076 & $X$ & & \\
\hline Elmidae & 0 & 0.217 & 0 & 0.607 & 0.001 & 0.667 & $\mathrm{X}$ & $X$ & $X$ \\
\hline
\end{tabular}

Min. = mínimo, Máx. = máximo, Olig. = oligotrófico, Meso. $=$ mesotrófico, Eut. $=$ eutrófico, $\mathrm{X}=$ presencia.

Min. $=$ Minimum, Max. $=$ maximum, Olig. $=$ oligotrophic, Meso. $=$ mesotrophic, Eut. $=$ eutrophic, $\mathrm{X}=$ presence.

de 0.5 unidades en el índice ICOMI (Tabla 2). En cuanto a la contaminación trófica, todos los géneros se encontraron en aguas eutróficas con concentraciones de fósforo desde $0.03 \mathrm{mg} / \mathrm{L}$. Además, Austrolimnius, Cylloepus, Heterelmis, Huleechius, Macrelmis, Neoelmis y Notelmis, toleraron concentraciones de fósforo total superiores a $0.1 \mathrm{mg} / \mathrm{L}$ y hasta $0.2 \mathrm{mg} / \mathrm{L}$ (Fig. 4B, Tabla 2).

\section{DISCUSIÓN}

La riqueza de Elmidae encontrada en este trabajo (22 géneros) representa el $78.5 \%$ de la riqueza genérica conocida a nivel nacional (González-Córdoba et al., 2019), y es comparable a la registrada por González-Córdoba et al. (2015a), González-Córdoba, Zúñiga, Mosquera-Murillo y Sánchez-Vásquez (2016) en las cuencas de los ríos Cauca y Atrato, con 18 géneros para los departamentos de Chocó y Valle del Cauca. Al involucrar más cuencas hidrográficas y regiones naturales, se encontraron cinco géneros más: Austrelmis, Gyrelmis, Neolimnius, Stegoelmis y Tyletelmis. Neocylloepus fue el único género registrado en los Andes y el Pacífico colombiano que no se encontró en el área de estudio, a pesar de que se evaluaron principalmente ecosistemas 
andinos. En la región Orinoquía (ventana No. 5) no se registraron los géneros Pilielmis y Hintonelmis, previamente registrados en el departamento del Meta por González-Córdoba, Zúñiga, Torres-Zambrano y Manzo (2015) y González-Córdoba et al. (2019). Mientras que el género Tyletelmis y las especies G. pusio, $G$. simplex, $X$. sandersoni, $X$. leechi, $X$. granatoides y $X$. teres, corresponden a nuevos registros para Colombia.

La presencia de bosques en la zona de ribera es una característica influyente en la calidad de los hábitats acuáticos y en esta investigación ejerció un efecto sobre la composición de Elmidae en los arroyos muestreados (prueba de t, $\mathrm{P}$ $=0.0002$ ). Los bosques ribereños puede influir sobre factores como mayor disponibilidad de sustratos y menor turbidez, sólidos disueltos y sedimentación, tal como ha sido evidenciado en otros estudios (Chará, Pedraza, \& Giraldo, 2008; Chará, Giraldo, Chará-Serna, \& Pedraza, 2010; Camargo-García, Chará, Giraldo-Sánchez, Chará-Serna, \& Pedraza, 2010; CharáSerna, Chará, Giraldo, Zúñiga, \& Allan, 2015) y pueden afectar los ensambles de Elmidae, en especial en sustratos como la hojarasca regulando su disponibilidad (Braun, Pires, Stenert, Maltchik, \& Kotzian, 2018).

En concordancia con el CCA, el aumento de sólidos suspendidos dificulta el asentamiento de Elmidae, la colonización y el aprovechamiento de recursos. Dicha variable se manifiesta principalmente por el aumento de limos, arcillas y microorganismos (Jiménez, 2000) y, al igual que la turbidez, puede afectar la productividad primaria y la biomasa de algas (Hynes, 1960; Chutter, 1969; Davies-Colley, Hickey, Quinn, \& Ryan, 1992). Por otro lado, los sólidos en suspensión pueden obstruir algunos mecanismos respiratorios por acumulación de partículas (Suren \& Jowett, 2001; Fossati, Wasson, Hery, Marin, \& Salinas, 2001). Al sedimentarse, los sólidos ocupan los microhábitats de mayor preferencia para los élmidos, disminuyendo la colonización. Todo esto puede generar mayor deriva y expone a los organismos a la depredación (Doeg \& Milledge, 1991; Suren \& Jowett, 2001; Connolly \& Pearson,
2007). De esta forma, Austrelmis, Austrolimnius, Gyrelmis, Hexanchorus, Neolimnius, Phanocerus, Pharceonus, Pseudodisersus, Stegoelmis y Xenelmis, serían más susceptibles a los efectos en el aumento de sólidos del agua. Mientras que estos efectos no serían tan importantes para Cylloepus, Heterelmis, Hexacylloepus, Huleechius, Macrelmis y Notelmis.

Los resultados indican que el oxígeno disuelto y el porcentaje de saturación de oxígeno en el agua son factores determinantes para el establecimiento de los élmidos. Además de los factores ambientales como temperatura, salinidad o presión atmosférica (que afectan la solubilidad del agua) (Chapman, 1996), la concentración de oxígeno puede disminuir por contaminantes orgánicos o exceso de nutrientes que eutrofizan el cuerpo de agua. Por esta razón, organismos sensibles a la disminución del oxígeno, serían también sensibles a la contaminación orgánica (Murgel, 1984; GarcíaCriado \& Fernández-Aláez, 2001; Sarriquet, Delettre, \& Marmonier, 2006; Hanson, Springer, \& Ramírez, 2010).

La variable deposición de sedimentos se valora positivamente en el ICH cuando hay menor cantidad de sedimentos acumulados en el fondo. Géneros de la subfamilia Larainae como Phanocerus, Pharceonus y Pseudodisersus, estuvieron favorecidos por valores altos de esta variable, lo cual puede deberse a que esta subfamilia tiene hábitos semiacuáticos $\mathrm{y}$ está frecuentemente asociada con las orillas y la zona de salpicadura de la corriente. Por esta misma razón, su presencia en los cuerpos de agua podría beneficiarse de una mayor heterogeneidad del hábitat, estabilidad de las orillas y el control de la erosión (Spangler \& Santiago, 1987; Fernandes \& Hamada, 2012; Maier, 2013); caso contrario a lo que ocurriría con Heterelmis y Hexacylloepus (Fig. 2B), los cuales pueden colonizar lechos afectados por la sedimentación, de manera que una mayor heterogeneidad del hábitat disminuiría su dominancia, al tener que competir por la explotación de los demás microhábitats disponibles.

Así mismo, diferentes organismos bentónicos requieren de una variedad de sustratos 
para colonizar en el fondo de las corrientes. $\mathrm{La}$ predilección de los élmidos por sustrato grueso y microhábitats en piedra es congruente con el registro de la familia en el lecho de los ríos (i.e. Spangler, 1980; Brown, 1991; Spangler \& Santiago-Fragoso, 1992; Laššová, Čiampor, \& Čiamporová-Zat'ovičová, 2014; Shepard \& Chaboo, 2015), en donde se ha encontrado que pocos géneros colonizan sustratos finos como arena o lodo (Lozano-Bravo et al., 2018). Según el CCA la disponibilidad de sustratos parece ser más decisiva en el asentamiento de Austrelmis, Hexanchorus, Onychelmis, Pharceonus y Pseudodisersus (Fig. 2), lo cual podría indicar que son selectivos de ciertos microhábitats y explicar su baja abundancia en muestreos. Por el contrario, Heterelmis, Hexacylloepus y Huleechius, suelen ser dominantes y generalistas, de manera que habitan sustratos poco colonizados por otros géneros.

En la franja altitudinal alta entre 3000 y 4000 m.s.n.m. únicamente se encontró el género Austrelmis y se asoció con valores altos de disponibilidad de oxígeno, lo que lo postula como un organismo indicador de buena calidad de agua en la zona altoandina de Colombia. Sin embargo, Austrelmis consors (Hinton, 1940b) se registra en el lago Titicaca (Bolivia) hasta los $20 \mathrm{~m}$ de profundidad con concentraciones de oxígeno de $6 \mathrm{mg} / \mathrm{L}$. Por esta razón, se infiere que algunas especies de este género tienen mayor tolerancia a la disminución de oxígeno, o que presentan alguna estrategia o adaptación que les permite sobrevivir en estas condiciones (Dejoux \& Iltis, 1991).

Géneros como Austrolimnius, Hexacylloepus, Macrelmis, Microcylloepus, Neoelmis, Notelmis, Onychelmis, Phanocerus y Pharceonus y, en mayor medida, Cylloepus, Heterelmis y Huleechius, con amplia distribución altitudinal, se ubican como organismos tolerantes a grados moderados de contaminación orgánica. Los tres últimos pudieron sobrevivir en condiciones de anoxia $(\leq 2 \mathrm{mg} / \mathrm{L})$, en las cuales muchos de los insectos acuáticos como plecópteros, tricópteros o efemerópteros no sobrevivirían (Hoback \& Stanley, 2001; Alonso
\& Camargo, 2005; Camargo \& Alonso, 2007; Resh, Buchwalter, Lamberti, \& Erikson, 2008).

La persistencia de los organismos acuáticos en condiciones de hipoxia o anoxia supone, en muchos casos, la inserción de rutas anaeróbicas en su metabolismo, la disminución de las tasas metabólicas, el incremento del volumen traqueal, entre otras (Hoback \& Stanley, 2001; Resh et al., 2008). Sin embargo, se desconoce qué adaptaciones utilizan Heterelmis, Huleechius y Cylloepus, para sobrevivir en las condiciones de bajo oxígeno en las que se registraron, que dificultan el mantenimiento del gradiente de $\mathrm{O}_{2}$ entre el agua y el interior de la burbuja plastrónica (Brown, 1987; Resh et al., 2008).

Algunos autores sugieren que una mayor cobertura de plastrón maximizaría el ingreso de oxígeno a la burbuja (Brown, 1987). Sin embargo, organismos con gran cantidad de tomento dorsal y ventral como Stenhelmoides, Stegoelmis o Xenelmis, se encontraron en este trabajo únicamente en aguas bien oxigenadas. Una explicación alternativa podría ser el establecimiento en microhábitats con corriente rápida, característica frecuentemente asociada a la familia. No obstante, es necesaria una exploración de los mecanismos fisiológicos o comportamentales y la eficiencia respiratoria de estos organismos en aguas poco oxigenadas (Dietrich \& Waringer, 1999).

Parámetros del cauce como la velocidad de corriente y profundidad, variables físico-químicas como temperatura, $\mathrm{pH}$, algunos nutrientes (nitritos, nitratos), turbidez y $\mathrm{DBO}_{5-20}{ }^{\circ} \mathrm{C}$ conteos bacterianos (coliformes totales) han sido identificadas como factores que influyen sobre la diversidad y composición de Elmidae (Braun, Salvarrey, Kotzian, Spies, \& Pires, 2014; Lozano-Bravo et al., 2018; AguileraGiraldo \& Vásquez-Ramos, 2019). Ninguna de dichas variables fue significativa en los análisis del CCA, el cual tuvo en cuenta las abundancias. Sin embargo, al analizar la presencia/ausencia de los géneros, se encontró que excesos en la concentración de nutrientes y sales ejercieron un efecto sobre la riqueza y composición de Elmidae. 
Para el caso de los élmidos, cantidades bajas de nitratos y ortofosfatos, disminuyen su principal fuente de alimento (algas y diatomeas) (Jeffries \& Mills, 1990; Vermonden et al., 2009), mientras que un incremento excesivo de nutrientes puede afectar su respiración. A pesar de que los nutrientes no actúan como agente tóxico directo sobre la supervivencia de estos organismos, el incremento de la carga orgánica y la demanda bioquímica de oxígeno (eutrofización) conllevan a la pérdida del oxígeno disponible. Por otro lado, elevados conteos bacterianos son indicio de la presencia de aguas residuales domésticas en un cuerpo de agua. No obstante, para este caso la relación con el déficit de oxígeno no es directa (Jeffries \& Mills, 1990; Vermonden et al., 2009), de ahí que no se encontró ninguna correspondencia con los valores de riqueza o abundancia de Elmidae.

Asimismo, los cambios en la temperatura pueden afectar a los organismos acuáticos en su metabolismo y ecología (Murgel, 1984; Chapman, 1996) y tiene una relación inversa con la altitud, la cual tuvo un efecto significativo sobre los élmidos. Pese a esto, se ha registrado que algunas especies de la familia logran sobrevivir en yacimientos de aguas termales $\left(29{ }^{\circ} \mathrm{C}\right.$ a 4000 m.s.n.m.) (Hinton, 1940b). La temperatura del agua es regulada también por factores más puntuales como la radiación solar (eliminación de bosques en zona de ribera), la aireación, el aumento de descargas residuales, la profundidad, el flujo del cuerpo de agua, entre otros (Chapman, 1996). Por lo que se mantiene la pregunta de cómo reaccionan los élmidos adaptados a su medio y temperatura, frente a la contaminación térmica o incluso al calentamiento global (Jacobsen, Schultz, \& Encalada, 1997; Jacobsen \& Martín, 2008).

No sólo las características intrínsecas y la calidad ecológica del agua afectan la supervivencia de los élmidos en un ambiente, si no que su distribución es reflejo de la evolución en determinado territorio. Es importante analizar los factores geográficos (latitud y longitud) a la hora de determinar qué organismos funcionan como bioindicadores. En el caso de estudio, esto es particularmente aplicable a géneros como Gyrelmis, Neolimnius, Stegoelmis y Tyletelmis (Fig. 2B) que se restringen a la zona más oriental de Colombia, en donde los Andes funcionan como una barrera geográfica. De ahí que no se encuentren dichos géneros en zonas con similares condiciones climáticas y altitudinales como la llanura del Pacífico o los valles interandinos.

La familia Elmidae fue sensible a la contaminación de diversos tipos que afectan principalmente la estabilidad de su ecosistema y la calidad del hábitat, más no son reflejo directo de afectaciones antrópicas (Tabla 2). Teniendo en cuenta el ICOSUS, es notable que la familia Elmidae es muy sensible al aumento de las partículas en suspensión. Valores por encima de 0.2 unidades en la escala ICOSUS indican descargas de material particulado que podría afectar el intercambio gaseoso, la alimentación, los sustratos para colonización de los élmidos y han sido registrados como antagonistas de la persistencia de la familia Elmidae (Miserendino \& Archangelsky, 2006; Miserendino \& Brand, 2009; Miserendino, Archangelsky, Brand, \& Epele, 2012), debido al incremento de la turbidez y la sedimentación (Fossati et al., 2001; Suren \& Jowett, 2001; Connolly \& Pearson, 2007).

Todos los géneros, en especial Cylloepus, Heterelmis, Huleechius, Macrelmis, Neoelmis y Austrolimnius, sobrevivieron en aguas catalogadas como eutróficas en relación con el contenido de fósforo total (Fig. 4B, Tabla 2). En términos generales, la familia podría sobrevivir a una incidencia moderada de contaminantes de tipo orgánico, como fuentes residuales difusas o actividad agrícola moderada, en tanto sean suplidos los requerimientos específicos de cada taxón, en particular la disponibilidad de oxígeno disuelto (García-Criado, 2000).

Según estos resultados, los géneros de Elmidae podrían ser más sensibles a los contaminantes inorgánicos como sales minerales disueltas, con la excepción de Heterelmis, Macrelmis, Microcylloepus, Neoelmis y Notelmis, los cuales mostraron ser tolerantes a grados moderados de contaminación mineral, 
condición que puede relacionarse con la escorrentía y la erosión del suelo circundante, así como explotación minera (García-Criado \& Fernández-Aláez, 2001; van Dam, 2003; Chará et al., 2010; Chará, Pedraza, Giraldo, \& Hincapié, 2007).

Existe una congruencia en los rangos de tolerancia de los géneros de Elmidae con las diferentes variables físico-químicas, las fuentes de contaminación y la calidad del agua (según el índice ICA-NSF). Estos resultados concuerdan con algunos trabajos en los que Elmidae se muestra tolerante a grados moderados de eutrofización y bajos niveles de contaminación de origen orgánico y mineral que corresponden a ambientes con calidad de agua buena a regular (García-Criado \& Aláez-Fernández, 1995; Barbour et al., 1999; Sánchez-Herrera, 2005; Miserendino \& Archangelsky, 2006; Hincapié-Montoya, 2017). Sin embargo, la respuesta de estos organismos a las fuentes de polución sigue ligada a la identidad de los mismos, por lo que es probable que varíe no sólo entre géneros como se mostró en este trabajo, sino también entre especies (García-Criado \& Fernández-Aláez, 1995; 2001; García-Criado, 2000; Zúñiga \& Cardona, 2009; Dos Santos et al., 2011; González-Meléndez, CaicedoQuintero, \& Aguirre-Ramírez, 2013).

Géneros como Heterelmis, Cylloepus, Neoelmis, Macrelmis y Microcylloepus, presentan amplia distribución, frecuencia en los muestreos y podrían sobrevivir en aguas con calidad de agua regular, por lo que estarían correctamente calificados con puntuaciones de 4, 6 o 7 unidades en índices bióticos preexistentes del tipo BMWP (Biological Monitoring Working Party Score), donde se tiene en cuenta sólo la familia (Sánchez-Herrera, 2005; Zúñiga \& Cardona, 2009; Roldán-Pérez, 2016). Sin embargo, géneros como Austrelmis, Gyrelmis, Hexanchorus, Neolimnius, Onychelmis, Phanocerus, Pharceonus, Pseudodisersus, Stegoelmis, Stenhelmoides y Tyletelmis, se encontraron en aguas con buena a excelente calidad. En estos casos, sería importante revaluar la asignación de puntajes para que reflejen de manera más precisa la respuesta de los diferentes ensambles de Elmidae a las condiciones del medio y su clasificación en términos de calidad de agua. Es necesario analizar de manera crítica y a partir de su composición genérica, el uso de la familia en índices bióticos de calidad del agua. Los resultados de este trabajo aportan información básica que podría considerarse en futuros estudios de bioindicación de calidad de agua, así como en la estructuración de nuevos índices ambientales o en la revaluación de los existentes.

En conclusión, como respuesta a las hipótesis y preguntas planteadas en este trabajo, encontramos que, en términos generales, Elmidae es sensible a las alterciones de su hábitat y la calidad ecológica del agua, pero los géneros tienen respuestas particulares a las condiciones en su hábitat y los factores de perturbación. Algunos géneros pueden ser agrupados por su sensibilidad o tolerancia a ciertos factores abióticos. Cylloepus, Heterelmis, Huleechius, Macrelmis, Microcylloepus y Neoelmis, son más tolerantes a las alterciones y se han mostrado generalistas en cuanto a la selección de hábitat, constituyendo los géneros más comunes en ríos colombianos, por lo que se deben catalogar como poco sensibles a la contaminación. Pero géneros como Disersus, Hexacylloepus, Notelmis, Onychelmis, Phanocerus, Pharceonus, Pseudodisersus y Xenelmis, son más selectivos y pueden ser catalogados como sensibles a los cambios en su medio. De manera que la potencialidad de la familia radica en trascender las dificultades taxonómicas para cada región de interés.

Declaración de ética: los autores declaran que todos están de acuerdo con esta publicación y que han hecho aportes que justifican su autoría; que no hay conflicto de interés de ningún tipo; y que han cumplido con todos los requisitos y procedimientos éticos y legales pertinentes. Todas las fuentes de financiamiento se detallan plena y claramente en la sección de agradecimientos. El respectivo documento legal firmado se encuentra en los archivos de la revista. 


\section{AGRADECIMIENTOS}

Al Departamento Administrativo de Ciencia, Tecnología e Innovación - Colciencias, por el proyecto financiado en la convocatoria de Jóvenes Investigadores e Innovadores 2016. Al proyecto Ganadería Colombiana Sostenible financiado por el Fondo para el Medio Ambiente Global (GEF) y el Gobierno del Reino Unido bajo la supervisión del Banco Mundial. A la Fundación CIPAV, sus co-financiadores e investigadores y asistentes, cuyos proyectos y esfuerzo de muestreo fueron esenciales para la recolección de los especímenes revisados y la información de las variables abióticas analizadas. A la Universidad del Valle y el Grupo de Investigaciones Entomológicas por facilitar la infraestructura para la revisión de muestras y consulta de bibliografía. Al Ingeniero Javier Holguín por facilitar las plantillas de cálculo para los índices ICA-FSN e ICOs.

\section{RESUMEN}

Introducción: Los élmidos son organismos acuáticos frecuentemente asociados con aguas corrientes, limpias y bien oxigenadas. Sin embargo, algunos géneros de esta familia también se encuentran en aguas moderadamente contaminadas, lo cual puede ser un reflejo de su tolerancia a algún grado de deterioro del hábitat. Objetivo: Determinar la sensibilidad o tolerancia a la contaminación y los principales factores que influyen en la presencia y composición taxonómica de Elmidae en microcuencas colombianas. Métodos: Se muestrearon 60 localidades entre 450 y $4000 \mathrm{msnm}$, principalmente en la región Andina, los muestreos se realizaron entre 2002 y 2013 con 70 eventos no simultáneos en cinco zonas. En un transecto de 100 m, se registraron datos físico-químicos, bacteriológicos y de calidad del hábitat (ICH), se hicieron arrastres con red D y Surber, y se determinaron los géneros de Elmidae. Se realizó un Análisis de Correspondencia Canónica entre las variables ambientales y la composición de Elmidae, las relaciones significativas se confirmaron con una prueba de Mantel y se realizó una prueba Mantel parcial incluyendo la ubicación geográfica como tercera matriz. Se calcularon los Índices de Contaminación ICOs y de Calidad de Agua ICA-FSN y se definieron intervalos de aparición de géneros para variables ambientales e índices. Para obtener las significancias estadísticas, se realizaron Análisis de Varianza ANOVA, pruebas t de Student y Modelos Lineales Generalizados MLG con distribución Poisson. Resultados: Se encontraron 22 géneros y 15 especies que representan el $78.5 \%$ de la riqueza nacional conocida. Tyletelmis y las especies Gyrelmis pusio, G. simplex, Xenelmis sandersoni, $X$. leechi, $X$. granatoides y $X$. teres, corresponden a nuevos registros para Colombia. Los principales factores que influyeron en la riqueza y composición de Elmidae fueron: saturación de oxígeno, deposición de sedimentos, sólidos suspendidos, disponibilidad de sustratos, altura, ubicación geográfica, conductividad, alcalinidad, turbidez, nitratos, nitrógeno amoniacal y fósforo. Conclusiones: Los géneros de Elmidae difieren en su tolerancia a la contaminación $\mathrm{y}$, por lo tanto, no pueden ser clasificados bajo el mismo grado de sensibilidad. Esta información puede ser útil para la clasificación de los géneros de Elmidae de acuerdo con su sensibilidad a los cambios en las condiciones ambientales y la degradación del hábitat, lo cual será un primer paso para la incorporación en un índice biótico de calidad de agua adaptado para las condiciones locales o el ajuste de los índices preexistentes.

Palabras clave: escarabajos acuáticos, lótico, oxígeno disuelto, calidad de agua, contaminación.

\section{REFERENCIAS}

Aguilera-Giraldo, I.A., \& Vásquez-Ramos, J.M. (2019). Distribución espacial y temporal de Elmidae (Insecta: Coleoptera) y su relación con los parámetros fisicoquímicos en el río Ocoa, Meta, Colombia. Revista de la Academia Colombiana de Ciencias Exactas, Físicas y Naturales, 43(166), 108-120.

Alonso, A., \& Camargo, J.A. (2005). Estado actual y perspectivas en el empleo de la comunidad de macroinvertebrados bentónicos como indicadora del estado ecológico de los ecosistemas fluviales españoles. Revista Ecosistemas, 14(3), 87-99.

Barbour, M., Gerritsen, J., Snyder, B.D., \& Stribling, J.B. (1999). Rapid Bioassessment Protocols for use in streams and wadeable rivers: Periphyton, benthic macroinvertebrates and fish (2 ${ }^{\text {nd }}$ Ed.). Washington D.C, USA: EPA.

Braun, B.M., Salvarrey, A.V.B., Kotzian, C.B., Spies, M.R., \& Pires, M.M. (2014). Diversity and distribution of riffle beetle assemblages (Coleoptera, Elmidae) in montane rivers of Southern Brazil. Biota Neotropica, 14(2), 1-11.

Braun, B., Pires, M., Stenert, C., Maltchik, L., \& Kotzian, C. (2018). Effects of riparian vegetation width and substrate type on riffle beetle community structure. Entomological Science, 21, 66-75.

Brocher, F. (1912). Recherches sur la respiration des insectes aquatiques adultes. Les elmides. Annales de Biologie Lacustre, 5, 136-179.

Brown, H.P. (1970). Neotropical dryopoids I. Xenelmis laura, a new species from Brazil (Coleoptera: Elmidae). The Coleopterists Bulletin, 24(3), 61-65. 
Brown, H.P. (1981). Key to the world genera of Larinae (Coleoptera, Dryopoidea, Elmidae), with descriptions of new genera from Hispaniola, Colombia, Australia, and New Guinea. Pan-Pacific Entomologist, 57(1), 76-104.

Brown, H.P. (1984). Neotropical Dryopoids, III. Major Nomenclatural Changes Affecting Elsianus Sharp and Macrelmis Motschulsky, with Checklists of Species (Coleoptera: Elmidae: Elminae). The Coleopterists Bulletin, 38(2), 121-129.

Brown, H.P. (1985). Xenelmis sandersoni, a new species of riffle beetle from Arizona and Northern Mexico (Coleoptera: Dryopoidea: Elmidae). The Southwestern Naturalist, 30(1), 53-57.

Brown, H.P. (1987). Biology of Riffle Beetles. Annual Review of Entomology, 32, 253-273.

Brown, H.P. (1991). Elmidae (Dryopoidea) (= Elminthidae, Helminthidae). Riffle beetles. In F.W. Stehr (Ed.), Immature insects (Vol. 2, pp. 404-407). Dubuque, Iowa, USA: Kendall/Hunt Publishing Co.

Camargo, J.A., \& Alonso, A. (2007). Contaminación por nitrógeno inorgánico en los ecosistemas acuáticos: problemas medioambientales, criterios de calidad del agua, e implicaciones del cambio climático. Revista Ecosistemas, 16(2), 98-110.

Camargo-García, J.C., Chará, J., Giraldo-Sánchez, L.P., Chará-Serna, A.M., \& Pedraza, G.X. (2010). Beneficios de los corredores ribereños de Guadua angustifolia en la protección de ambientes acuáticos en la Ecorregión Cafetera de Colombia. 1. Efectos sobre las propiedades del suelo. Revista Recursos Naturales y Ambiente, 61, 53-59.

Chapman, D.V. (1996). Water Quality Assessments: A guide to use Biota, Sediments and Water Environmental Monitoring ( $2^{\text {nd }}$ Ed.). London, UK: UNESCO, WHO, UNEP.

Chará, J. (2003). Manual para la evaluación biológica de ambientes acuáticos en microcuencas ganaderas. Santiago de Cali: Fundación CIPAV.

Chará, J., Giraldo, L.P., Chará-Serna, A.M., \& Pedraza, G.X. (2010). Beneficios de los corredores ribereños de Guadua angustifolia en la protección de ambientes acuáticos en la Ecorregión Cafetera de Colombia. 2. Efectos sobre la escorrentía y captura de nutrientes. Recursos Naturales y Ambiente, 61, 60-66.

Chará, J., Pedraza, G., \& Giraldo, L.P. (2008). Corredores ribereños como herramienta de protección de ambientes acuáticos en zonas ganaderas. En E. Murgueitio, C. Cuartas, \& J.F. Naranjo (Eds.), Ganadería del futuro: Investigación para el desarrollo (pp. 111130). Santiago de Cali, Colombia: Fundación CIPAV.

Chará, J., Pedraza, G., Giraldo, L., \& Hincapié, D. (2007). Efecto de los corredores ribereños sobre el estado de quebradas en la zona ganadera del río La Vieja, Colombia. Agroforestería de Las Américas, $45,72-78$.

Chará-Serna, A.M., Chará, J., Giraldo, L.P., Zúñiga, M. del C., \& Allan, J.D. (2015). Understanding the impacts of agriculture on Andean stream ecosystems of Colombia: a causal analysis using aquatic macroinvertebrates as indicators of biological integrity. Freshwater Science, 34(2), 727-740.

Chutter, F.M. (1969). The effects of silt and sand on the invertebrate fauna on streams and rivers. Hydrobiologia, 34, 57-76.

Connolly, N.M., \& Pearson, R.G. (2007). The effect of fine sedimentation on tropical stream macroinvertebrate assemblages: a comparison using flowthrough artificial stream channels and recirculating mesocosms. Hydrobiologia, 592, 423-438.

Davies-Colley, R.J., Hickey, C.W., Quinn, J.M., \& Ryan, P.A. (1992). Effects of clay discharges on streams. 1. Optical properties and epilithon. Hydrobiologia, $248,215-234$.

De Cáceres, M., \& Legendre, P. (2009). Associations between species and groups of sites: indices and statistical inference. Ecology, 90, 3566-3574.

Delève, J. (1968). Coleoptera Elminthidae. In N. Leleupet \& J. Leleup (Eds), Résultats scientifiques. Mission zoologique belge aux îles Galapagos et en Ecuador (pp. 209-272). Bruxelles, Belgique: Institut Royal des Sciences Naturelles de Belgique.

Dejoux, C., \& Iltis, A. (1991). El lago Titicaca: Síntesis del conocimiento limnológico actual. La Paz, Bolivia: Institut Français de Recherche Scientifique pour le Développement \& Instituto de Historia Social en Bolivia.

Dietrich, F., \& Waringer, J.A. (1999). Distribution patterns and habitat characterization of Elmidae and Hydraenidae (Insecta: Coleoptera) in the Weidlingbach near Vienna, Austria. International Review of Hydrobiology, 84(1), 1-15.

Doeg, T.J., \& Milledge, G.A. (1991). The effects of experimentally increasing suspended sediment concentrations on macroinvertebrate drift. Australian Journal of Marine and Freshwater Research, 42(5), 519-526.

Dos Santos, D.A., Molineri, C., Reynaga, M.C., \& Basualdo, C. (2011). Which index is the best to assess stream health? Ecological Indicators, 11(2), 582-589.

Escherich, T. (1885). Dïe Darmbakterien der Säuglings und Neugeborenen. Fortschritte Medizin, 3, 515-522.

Fernandes, A.S., \& Hamada, N. (2012). Description and notes on the bionomics of a new species of Potamophilops Grouvelle, 1896 (Coleoptera: Elmidae: 
Larainae), from the Cerrado biome in Brazil. Journal of Natural History, 46(11-12), 717-727.

Fossati, O., Wasson, J.G., Hery, C., Marin, R., \& Salinas, G. (2001). Impact of sediment releases on water chemistry and macroinvertebrate communities in clear water Andean streams (Bolivia). Archiv für Hydrobiologie, 151(1), 33-50.

García-Criado, F. (2000). Distribución y autoecología de Coleóptera acuáticos en ríos afectados por minería del carbón (cuenca del Sil, León, España) 1. Elmidae. Boletín de la Asociación Española de Entomología, 24(3-4), 105-124.

García-Criado, F., \& Fernández-Aláez, C. (1995). Aquatic Coleoptera (Hydraenidae and Elmidae) as indicators of the chemical characteristics of water in the Orbigo River basin (NW Spain). Annales de LimnologieInternational Journal of Limnology, 31(3), 185-199.

García-Criado, F., Fernández-Aláez, C., \& FernándezAláez, M. (1999). Environmental variables influencing the distribution of Hydraenidae and Elmidae assemblages (Coleoptera) in a moderately-polluted river basin in north-western Spain. European Journal of Entomology, 96, 37-44.

García-Criado, F., \& Fernández-Aláez, M. (2001). Hydraenidae and Elmidae assemblages (Coleoptera) from a Spanish river basin: good indicators of coal mining pollution? Archiv für Hydrobiologie, 150(4), 641-660.

González-Córdoba, M., Zúñiga, M. del C., \& Manzo, V. (2015a). Riqueza genérica y distribución de Elmidae (Insecta: Coleoptera, Byrrhoidea) en el departamento del Valle del Cauca, Colombia. Biota Colombiana, 16(2), 51-74.

González-Córdoba, M., Zúñiga, M. del C., Torres-Zambrano, N.N., \& Manzo, V. (2015b). Primer registro de las especies Neolimnius palpalis Hinton y Pilielmis apama Hinton (Coleoptera: Elmidae: Elminae) para Colombia y la cuenca del río Orinoco. Boletín del Museo de Entomología de la Universidad del Valle, 16(1), 27-33.

González-Córdoba, M., Zúñiga, M. del C., MosqueraMurillo, Z., \& Sánchez-Vásquez, S. (2016). Riqueza y distribución de Elmidae (Insecta: Coleoptera: Byrrhoidea) en el departamento del Chocó, Colombia. Intropica, 11(1), 85-95.

González-Córdoba, M., Zúñiga, M. del C., Manzo, V., Granados-Martínez, C., \& Panche, J. (2019). Nuevos registros y datos de distribución de diez especies y cuatro géneros de élmidos (Coleoptera: Elmidae) para Colombia. Boletín Científico Centro de Museos. Museo de Historia Natural, 23(1), 247-266.

González-Meléndez, V., Caicedo-Quintero, O., \& AguirreRamírez, N.J. (2013). Aplicación de los Índices de Calidad de Agua NSF, DINIUS y BMWP en la quebrada La Ayurá, Antioquia, Colombia. Revista Gestión y Ambiente, 16(1), 97-108.

Hammer, Ø., Harper, D.A., \& Ryan, P.D. (2001). PAST: paleontological statistics software package for education and data analysis. Palaeontologia Electronica, 4(1), 9 .

Hanson, P., Springer, M., \& Ramírez, A. (2010). Capítulo 1: Introducción a los grupos de macroinvertebrados acuáticos. Revista de Biología Tropical, 58, 3-37.

Harpster, H.T. (1944). The gaseous plastron as a respiratory mechanism in Stenelmis quadrimaculata Horn Dryopidae. Transactions of the American Microscopical Society, 63(1), 1-26.

Hincapié-Montoya, D. (2017). Elmidae (Coleoptera) o escarabajos de aguas rápidas. Una actualización para Colombia. Boletín del Museo Entomológico Francisco Luís Gallego, 9(3), 4-15.

Hinton, H.E. (1939). On some new genera and species of Neotropical Dryopoidea (Coleoptera). Transactions of the Royal Entomological Society of London, 89(3), 23-45.

Hinton, H.E. (1940a). A monograph of Gyrelmis gen. n., with a study of the variation of the internal anatomy (Coleoptera, Elmidae). Transaction Royal Entomological Society of London, 90, 375-409.

Hinton, H.E. (1940b). The Percy Sladen Trust expedition to Lake Titicaca in 1937 under the leadership of Mr. H. Cary Gilson. VII. The Peruvian and Bolivian species of Macrelmis Motsch. (Coleoptera, Elmidae). Transactions of the Royal Entomological Society, 1(2), 117-147.

Hinton, H.E. (1946). A key to the species of Xenelmis Hinton with descriptions of three new species (Coleoptera, Elmidae). Entomologist's Monthly Magazine, 83, 237-241.

Hinton, H.E. (1972). Two new genera of South American Elmidae (Coleoptera). The Coleopterists Bulletin, $37-41$.

Hoback, W.W., \& Stanley, D.W. (2001). Insects in hypoxia. Journal of Insect Physiology, 47(6), 533-542.

Hynes, H.B.N. (1960). The Biology of Polluted Waters. Toronto, Canada: University of Toronto Press.

Jacobsen, D., \& Marín, R. (2008). Bolivian Altiplano streams with low richness of macroinvertebrates and large diel fluctuations in temperature and dissolved oxygen. Aquatic Ecology, 42(4), 643-656.

Jacobsen, D., Schultz, R., \& Encalada, A. (1997). Structure and diversity of stream invertebrate assemblages: the influence of temperature with altitude and latitude. Freshwater Biology, 38(2), 247-261. 
Jäch, M., Kodada, J., Brojer, M., Shepard, W.D., \& Čiampor, J.F. (2016). Coleoptera: Elmidae and Protelmidae. Brill. World Catalogue of Insects (Vol. 14). Leiden/Boston: Brill.

Jeffries, M., \& Mills, D. (1990). Freshwater Ecology: Principles and Applications. London, UK: Belhaven Press.

Jiménez, A.A. (2000). Determinación de los parámetros fisico-químicos de calidad de las aguas. Gestión Ambiental, 2(23), 12-19.

Laššová, K., Čiampor, J.F., \& Čiamporová-Zat'ovičová, Z. (2014). Two new Larainae species from Guayana region, Venezuela (Coleoptera: Elmidae). Zootaxa, 3753(2), 187-195.

Lozano-Bravo, J.L., Guevara-Cardona, G., \& ReinosoFlórez, G. (2018). Diversidad espacio-temporal de la familia Elmidae (Insecta: Coleoptera) en la quebrada las Perlas (Ibagué, Colombia). Revista de la Asociación Colombiana de Ciencias Biológicas, 30, 61-71.

Maier, C.A. (2013). A revision of the Larainae (Coleoptera, Elmidae) of Venezuela, with description of nine new species. ZooKeys, 329, 33-91.

Maier, C.A., \& Spangler, P.J. (2011). Hypsilara royi gen. n. and sp. nov. (Coleoptera, Elmidae, Larainae) from Southern Venezuela, with a revised key to Larainae of the Western Hemisphere. ZooKeys, 116, 25-36.

Manzo, V. (2005). Key to the South American genera of Elmidae (Insecta: Coleoptera) with distributional data. Studies on Neotropical Fauna and Environment, 40, 201-208.

Manzo, V. (2006). A review of the American species of Xenelmis Hinton (Coleoptera: Elmidae) with a new species from Argentina. Zootaxa, 1242, 53-68.

Manzo, V. (2013). Los élmidos de la región Neotropical (Coleoptera: Byrrhoidea: Elmidae): diversidad y distribución. Revista de la Sociedad Entomológica Argentina, 72(3-4), 199-212.

Manzo, V., \& Archangelsky, M. (2008). A key to the known larvae of South American Elmidae (Coleoptera: Byrrhoidea), with a description of the mature larva of Macrelmis saltensis Manzo. Annales de LimnologieInternational Journal of Limnology, 44(1), 63-74.

Miserendino, M.L., \& Archangelsky, M. (2006). Aquatic Coleoptera distribution and environmental relationships in a large Patagonian river. International Review of Hydrobiology, 91(5), 423-437.

Miserendino, M.L., \& Brand, C. (2009). Environmental effects of urbanization on streams and rivers in Patagonia (Argentina): the use of macroinvertebrates in monitoring. In J. Daniels (Ed.), Advances in Environmental Research (Vol. 6, pp. 183-220). New York, USA: NOVA.
Miserendino, M.L., Archangelsky, M., Brand, C., \& Epele, L.B. (2012). Environmental changes and macroinvertebrate responses in Patagonian streams (Argentina) to ashfall from the Chaitén Volcano (May 2008). Science of the Total Environment, 424, 202-212.

Murgel, S. (1984). Limnología sanitaria. Estudios de la polución de aguas continentales. Monografía 28. Washington D.C., EEUU: Secretaría General de la OEA.

Oksanen, J., Blanchet, F.G., Kindt, M.F.R., Legendre, P., McGlinn, D., Minchin, P.R. ... Wagner, H. (2018). Vegan: Community Ecology Package. R package version 2.5-3. Retrieved from https://CRAN.R-project. org/package= $=$ vegan

Ott, W.R. (1978). Environmental Indices: Theory and Practice. Michigan, USA: Ann Arbor Science.

Passos, M.I.S., Nessimian, J.L., \& Dorvillé, F.M. (2003). Life strategies in an elmid (Insecta: Coleoptera: Elmidae) community from a first order stream in the Atlantic Forest, Southeastern Brazil. Acta Limnologica Brasiliensia, 15, 29-36.

Perkins, P.D., \& Steiner, W.E. (1981). Two new Peruvian species of the riffle beetles genus Xenelmis (Coleoptera: Elmidae). Pan-Pacific Entomologist, 57(1), 306-312.

Picazo, F., Millan, A., \& Doledec, S. (2012). Are patterns in the taxonomic, biological and ecological traits of water beetles congruent in Mediterranean ecosystems? Freshwater Biology, 57(11), 2192-2210.

R Core Team (2018). R: A language and environment for statistical computing. R Foundation for Statistical Computing, Vienna, Austria. Retrieved from https:// www.R-project.org/

Ramírez, A., Restrepo, R., \& Viña-Viscaíno, G. (2000). Cuatro índices de contaminación para caracterización de aguas continentales. Formulaciones y aplicaciones. ECOPETROL-IPC, Bucaramanga. Ciencia, Tecnología y Futuro, 1, 135-153.

Resh, V.H., Buchwalter, D.B., Lamberti, G.A., \& Erikson, C.H. (2008). Aquatic insect respiration. In R.W. Merritt, K.W. Cummings, M.B. Berg (Eds), An Introduction to the Aquatic Insects of North America (4 ${ }^{\text {th }}$ Ed., pp. 39-53). Dubuque, USA: Kendall Hunt Publishing Company.

Roldán-Pérez, G. (2016). Los macroinvertebrados como bioindicadores de la calidad del agua: cuatro décadas de desarrollo en Colombia y Latinoamérica. Revista de la Academia Colombiana de Ciencias Exactas, Físicas y Naturales, 40(155), 254-274.

Sampaio, B.H.L., Passos, M.I.S., \& Ferreira, N. (2015). New species and new records of Xenelmis Hinton (Coleoptera: Elmidae) from Southeastern Brazil. Zootaxa, 3936(1), 115-122. 
Sánchez-Herrera, M.J. (2005). El índice biológico BMWP (Biological Monitoring Working Party Score), modificado y adaptado al cauce principal del río Pamplonita norte de Santander. Bistua: Revista de la Facultad de Ciencias Básicas, 3(2), 54-67.

Sarriquet, P.E., Delettre, Y.R., \& Marmonier, P. (2006). Effects of catchment disturbance on stream invertebrates: comparison of different habitats (vegetation, benthic and interstitial) using bio-ecological groups. Journal Annales de Limnologie-International of Limnology, 42(4), 205-219.

Sharp, D. (1882). Insecta, Coleoptera. (Haliplidae, Dytiscidae, Gyrinidae, Hydrophilidae, Heteroceridae, Parnidae, Georissidae, Cyathoceridae). In F.D. Godman \& O. Salvin (Eds.), Biologia Centrali-Americana (xv, p. 824). London, UK: Taylor y Francis.

Shepard, W.D., \& Chaboo, C.S. (2015). Beetles (Coleoptera) of Peru: A Survey of the Families. Elmidae. Journal of the Kansas Entomological Society, 88(2), 167-168.

Spangler, P.J. (1980). V. Aquatic Coleoptera. The results of the Catherwood Foundation Bolivian-Peruvian Altiplano Expedition. Part I. Aquatic insects except Diptera. Monographs of the Academy of Natural Sciences of Philadelphia, 132, 199-213.

Spangler, P.J. (1981). Two new genera of phreatic elmid beetles from Haiti. Bijdragen tot de Dierkunde, 51(2), 375-387.

Spangler, P.J. (1990). A revision of the Neotropical aquatic beetle genus Stegoelmis (Coleoptera: Elmidae). Smithsonian Contributions to Zoology, 502, 1-52.

Spangler, P.J., \& Perkins, P.D. (1989). Revision of the Neotropical aquatic beetle genus Stenhelmoides (Coleoptera: Elmidae). Smithsonian Contributions to Zoology, 479, 1-63.

Spangler, P.J., \& Santiago, S. (1987). A revision of the Neotropical Aquatic beetle genera Disersus, Pseudodisersus, and Potamophilops (Coleoptera: Elmidae). Smithsonian Contributions to Zoology, 446, 1-40.

Spangler, P.J., \& Santiago, S. (1991). A new species and new records from Colombia of the water beetle genus
Onychelmis Hinton (Coleoptera: Elmidae: Elminae). Proceedings of the Entomological Society of Washington, 93(2), 495-498.

Spangler, P.J., \& Santiago-Fragoso, S. (1992). The aquatic beetle subfamily Larainae (Coleoptera: Elmidae) in Mexico, Central America and the West Indies. Smithsonian Contributions to Zoology, 528, 1-74.

Stride, G.O. (1955). On the respiration of an aquatic African beetle, Potamodytes tuberosus Hinton. Annals of the Entomological Society of America, 48(5), 344-351.

Suren, A.M., \& Jowett, I.G. (2001). Effects of deposited sediment on invertebrate drift: An experimental study. New Zealand Journal of Marine and Freshwater Research, 35(4), 725-737.

Van Dam, O. (2003). Eco-hydrological functions and threats of tropical rain forests at different spatial scales. In P.A. Zuidema (Ed.), Tropical forests in multi-functional landscape (pp. 53-63). Utrecht, The Netherlands: Prince Bernhard Centre for International Nature Conservation.

Vermonden, K., Leuven, R.S., van der Velde, G., van Katwijk, M.M., Roelofs, J.G., \& Hendriks, A.J. (2009). Urban drainage systems: An undervalued habitat for aquatic macroinvertebrates. Biological Conservation, 142(5), 1105-1115.

Von Ellenrieder, N. (2007). Composition and structure of aquatic insect assemblages of Yungas mountain cloud forest streams in NW Argentina. Revista de la Sociedad Entomológica Argentina, 66(3-4), 57-76.

Zúñiga, M. del C., \& Cardona, W. (2009). Bioindicadores de calidad de agua y caudal ambiental: Caso del Río Meléndez (Valle del Cauca, Colombia). En J. Cantera, Y. Carvajal, \& L. Castro (Eds.), Caudal ambiental: Conceptos Experiencias y Desafios (pp. 167-198). Cali, Colombia: Programa Editorial de la Universidad del Valle. 